\title{
Energy and Water Sustainability in the U.S. Biofuel Industry
}

\section{Energy Systems Division}
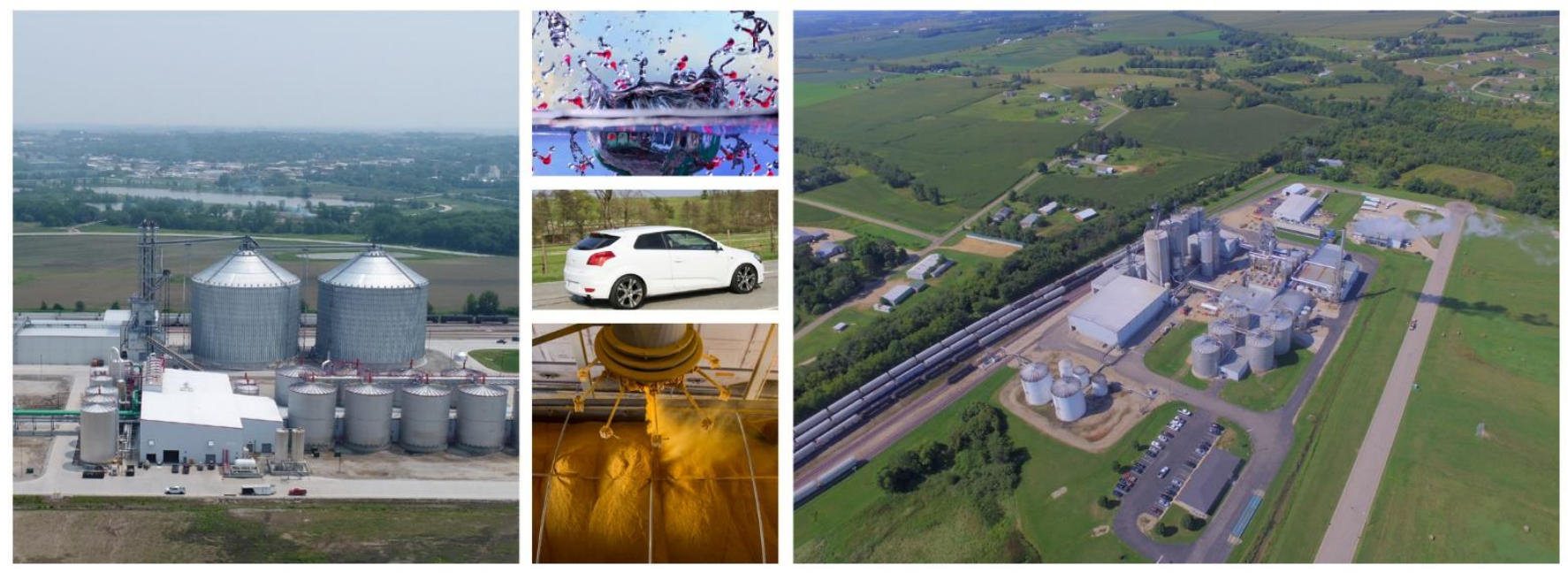


\title{
Cover image credit
}

Renewable Fuel Association provided ethanol plants photos, Growth Energy provided

DDGS processing photo.

\author{
About Argonne National Laboratory \\ Argonne is a U.S. Department of Energy laboratory managed by UChicago Argonne, LLC \\ under contract DE-AC02-06CH11357. The Laboratory's main facility is outside Chicago, \\ at 9700 South Cass Avenue, Lemont, Illinois 60439. For information about Argonne \\ and its pioneering science and technology programs, see www.anl.gov.
}

\section{DOCUMENT AVAILABILITY}

Online Access: U.S. Department of Energy (DOE) reports produced after 1991 and a growing number of pre-1991 documents are available free via DOE's SciTech Connect (http://www.osti.gov/scitech/).

Reports not in digital format may be purchased by the public from the National Technical Information Service (NTIS):

U.S. Department of Commerce

National Technical Information Service

5301 Shawnee Road

Alexandria, VA 22312

www.ntis.gov

Phone: (800) 553-NTIS (6847) or (703) 605-6000

Fax: (703) 605-6900

Email: orders@ntis.gov

Reports not in digital format are available to DOE and DOE contractors from the Office of Scientific and Technical Information (OSTI):

U.S. Department of Energy

Office of Scientific and Technical Information

P.O. Box 62

Oak Ridge, TN 37831-0062

www.osti.gov

Phone: (865) 576-8401

Fax: (865) 576-5728

Email: reports@osti.gov

\section{Disclaimer}

This report was prepared as an account of work sponsored by an agency of the United States Government. Neither the United States Government nor any agency thereof, nor UChicago Argonne, LLC, nor any of their employees or officers, makes any warranty, express or implied, or assumes any legal liability or responsibility for the accuracy, completeness, or usefulness of any information, apparatus, product, or process disclosed, or represents that its use would not infringe privately owned rights. Reference herein to any specific commercial product, process, or service by trade name, trademark, manufacturer, or otherwise, does not necessarily constitute or imply its endorsement, recommendation, or favoring by the United States Government or any agency thereof. The views and opinions of document authors expressed herein do not necessarily state or reflect those of the United States Government or any agency thereof, Argonne National Laboratory, or UChicago Argonne, LLC. 
ANL/ESD-19/5

\section{Energy and Water Sustainability in the U.S. Biofuel Industry}

by

May Wu

Energy Systems Division, Argonne National Laboratory

June 2019 



\section{CONTENTS}

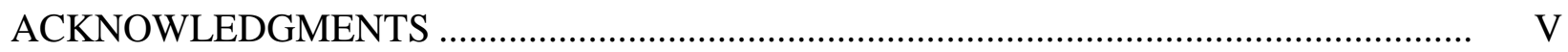

EXECUTIVE SUMMARY ................................................................................. 1

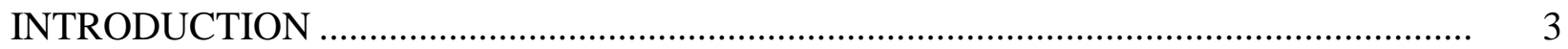

METHODOLOGY …………………………………………………………….. 5

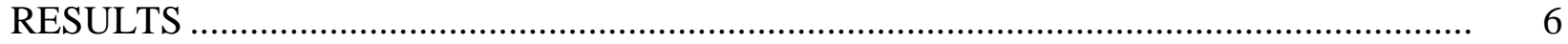

Production Capacity and Plant Start-up Year................................................................... 6

Feedstock Sources ...................................................................................................... 9

Product Portfolio and Yields ................................................................................... 11

Fuel and Electricity Use ........................................................................................ 13

Energy and Water Use in Distillers Grain Processing................................................... 17

Water Resources and Water Intensity ....................................................................... 19

Water Conservation through Increased Use, Recycle and Reuse..................................... 22

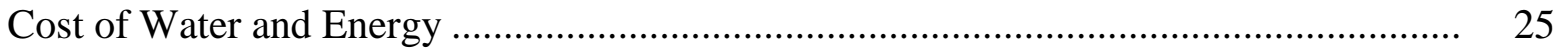

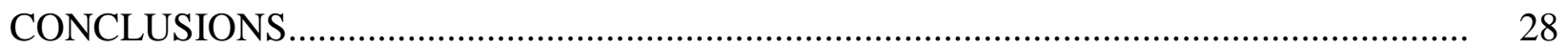

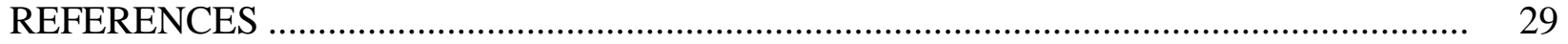

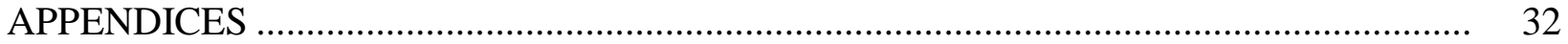

1 Survey Forms for Ethanol Plants............................................................................. 32

2 Survey Form for Biodiesel Plants............................................................................... 42

FIGURES

1 Distribution of dry-mill biofuel plants by geographic regions and start-up year.............. 7

2 Ethanol production capacity............................................................................. 8

3 Production capacity under operation in 2017 compared to maximum design capacity.... 9

$4 \quad$ Feedstock of dry-mill ethanol-producing facilities. .................................................... 10

5 Maximum, 75th percentile, median, 25th percentile, and minimum values of biofuel yield derived from grain fermentation and from grain and corn kernel fiber co-processing.

6 Yields of coproducts DDGS, WDGS, MWDG, syrup, and $\mathrm{CO}_{2}$ gas. ........................... 12

7 Source of thermoenergy and maximum, 75th percentile, median, 25th percentile, and minimum values of thermoenergy consumption.............................................................. 13

8 Source of electricity in dry-mill ethanol plants. .......................................................... 14

9 Statistical analysis of electricity consumption in ethanol plants: maximum, 75th percentile, median, 25th percentile, and minimum values............................................ 15

10 Electricity demand, grid electricity use, and displacement by on-site generation in example facilities. 


\section{FIGURES (CONT.)}

11 Electricity consumption based on product for ethanol plants that export $\mathrm{CO}_{2} \ldots \ldots \ldots \ldots \ldots . .16$

12 Cooling system energy usage: maximum, 75th percentile, median, 25 th percentile, and minimum value of electricity requirement.

13 Electricity and thermoenergy used for ethanol production and coproducts drying per gallon of biofuel produced.

14 Moisture content of coproducts DDGS, WDGS, MWDG, and syrup........................... 18

15 Types of water resources used in biofuel production, by number of facilities................ 20

16 Types of water resources used in biofuel production, by production volume................. 20

17 Water intensity: maximum, 75th percentile, median, 25th percentile, and minimum value of water consumption per 100 million gallons of ethanol produced, and total gallons of water consumption per production facility.

18 Cooling water treatment technologies

19 Cooling-tower cycles of concentration: maximum, 75th percentile, median, 25th percentile, and minimum value of cycles of concentration.

20 Boiler cycles of concentration: maximum, 75th percentile, median, 25th percentile, and minimum values.

21 Fate of wastewater from biofuel production facilities.

22 Maximum, 75th percentile, median, 25th percentile, and minimum freshwater cost to ethanol facilities in dollars per 1000 gallons of fresh water.

23 Natural gas cost: maximum, 75th percentile, median, 25th percentile, and minimum values.

\section{TABLES}

1 Changes in ethanol production from dry mills from 2007 to 2017 ............................ 7

2 Source of feedstock supply to biorefineries by state ........................................... 10 


\section{ACKNOWLEDGMENTS}

This work was carried out with the support of Kristen Johnson of the U.S. Department of Energy's Office of Energy Efficiency and Renewable Energy, Bioenergy Technologies Office (BETO). The author would like to thank Johnathan Male and Kristen Johnson, both of BETO, for the review of this report; Renewable Fuels Association, Growth Energy, and National Biodiesel Board for inputs to survey questionnaire development and support of data collection; and EcoLab Nalco Water for water system operational knowledge and valuable suggestions for survey questionnaire development. We thank Hui Xu and Mi-Ae Ha, both of Argonne National Laboratory, for data entry and initial processing; and Argonne Communications \& Public Affairs Office for editing and formatting of this report. 


\title{
ENERGY AND WATER SUSTAINABILITY IN THE U.S. BIOFUEL INDUSTRY
}

\author{
May Wu \\ Argonne National Laboratory
}

\section{EXECUTIVE SUMMARY}

The progress of technology development for conventional and advanced biofuel production processes in the U.S. has been reviewed by several groups over the last two decades (Warner et al. 2017; Mueller and Kwik 2013; Wu et al. 2009; Wu 2008; Shapouri and Gallagher 2005). Together, these surveys have demonstrated a continuous improvement of productivity, diversified product portfolio, and progress in resource conservation. Data gathered on production capacity, yield, energy use, and product portfolio help to establish industrial benchmarks and to evaluate the environmental sustainability of the industry, which is critical to addressing the Food-Energy-Water (FEW) nexus that is closely linked to bioenergy production. In 2018, Argonne National Laboratory, with support from the U.S. Department of Energy, Office of Energy Efficiency and Renewable Energy, Bioenergy Technologies Office, conducted a survey of biofuel producers in the United States. The survey covered a full range of plant operation parameters, including plant capacity, feedstock, product, production volume, coproducts, water resources, water treatment, water usage, wastewater management, and process fuel and electricity consumption, as reflected in 2017 plant operation data. This report presents the most up-to-date analysis of commercial-scale plants in the U.S., including facilities producing fuels from both starch and cellulosic materials. As of this time, this is the first survey that includes the comprehensive recording of water resources, water use, and water and wastewater management for the U.S. biofuel industry at the facility level. Data presented in this study reflect primarily information on full-scale ethanol production from dry mills that was available at the time of survey. Results highlight the complexity of energy and water resource use in process steps and the role of water conservation, recycling, and reuse in advancing the production of biofuel and its contribution to the bioeconomy and the FEW nexus.

In this study, we analyze technology factors and management approaches that affect plant water footprint, water conservation, and recycle/reuse. Survey data were processed, screened and examined. Statistical analysis was applied to all 77 surveyed parameters. We conducted a rigorous analysis, which was then aggregated for presentation. Results from this survey are compared with those of previous industry surveys, and changes that increase the environmental profile, productivity, and potential environmental benefits are estimated. The values presented in this report represent an average of current technologies weighted by the respective volumes of biofuel produced by these technologies. The survey found that co-processing of corn kernel fiber with grain to produce ethanol has become a promising approach, with a $2.5 \%$ increase in yield compared to grain processing alone. In 2017, 2.88 gallons of denatured ethanol were produced from the starch and fiber of a bushel of grain, as compared to 2.81 gallons produced from starch alone. Forty-one percent of respondents produce ethanol from corn fiber. The biofuel industry has made a concerted effort to conserve resources, diversify energy sources, and recycle and 
reuse water. Five percent of plants have implemented on-site electricity generation to replace grid electricity, and several plants have become net electricity exporters. Water intensity has decreased by $12 \%$ since 2011 and by $54 \%$ in the 19 years between 1998 and 2017. It takes 2.65 gallons of freshwater to produce a gallon of denatured ethanol. Newer plants with improved energy and steam integration dominate biofuel plants. $\mathrm{CO}_{2}$ extraction and export is reported in $14 \%$ of respondents. $\mathrm{CO}_{2}$ production is on the rise because of increased revenue, despite an increase in electricity expenditure for compressing $\mathrm{CO}_{2}$. In the area of water resource use, biofuel plants have diversified their water sources by using power plant cooling water and municipal reclaimed water in addition to well water and city water supply. Water and wastewater management is progressing toward zero liquid discharge (ZLD). The survey found that $42 \%$ of facilities achieved ZLD by increasing in-plant water reuse and recycling. Plants have also conserved water and energy by increasing production of wet distillers grain and modified wet distillers grain, reducing the demand for natural gas and electricity for drying. The water content in these coproducts is reused as a part of animals' diets in feedlots. Analysis of the survey results demonstrated that the production practices of the biofuel industry address the FEW nexus in a way that is energy-efficient, water-efficient, and environmentally sustainable. 


\section{INTRODUCTION}

Balancing energy and food demand in a way that is environmentally sustainable in the context of the Food-Energy-Water (FEW) nexus is being recognized as a centerpiece of the growing energy sector (Liu et al. 2018; Grubert and Sanders 2018). Water and energy are resources that are cross-linked in bio-based energy. Manufacturing of biofuels from conventional and cellulosic feedstock has its unique place in the FEW nexus because it requires process technologies that produce biofuel, animal feed, food, biopower, and chemical feedstock (LópezDíaz et al. 2018; Martín and Grossmann 2015). Biofuel production activities closely interact with land use in agriculture and forestry, require energy and water input, and generate wastewater and emissions (Silalertruksa and Gheewala 2019). In recent decades, as production technology has progressed from conventional starch-based biofuel to cellulosic biofuel and to advanced hydrocarbons derived from algae and other cellulosic feedstock, the industry is experiencing a revolutionary shift towards biorefining of a broader range of products. Indeed, the biofuel industry plays a role in achieving bioeconomic sustainability - a key goal in the strategy announced by multiple federal agencies to accelerate innovative technologies that harness the nation's biomass resources for affordable biofuels, bioproducts, and biopower (BR\&D, 2019). In this context, monitoring the energy efficiency and environmental sustainability of production with the anticipation of consistent growth is a fundamental strategy for the biofuel industry.

Water use, water availability, and wastewater management are among the critical factors that affect environmentally sustainable growth in manufacturing sectors (Thiede et al. 2017; Oliveira et al. 2019; Wu et al. 2018). Because the availability of water for production varies geographically depending on regional water richness (Xu et al. 2019), and competing demands arise from multiple sectors and population growth (Fang and Jawitz 2019), extraction of freshwater resources at a rate that exceeds the renewable freshwater inputs would increase water stress in a region. Decreased water resources would interrupt existing operations and constrain new project development. In particular, the effect of limited water resources could be detrimental in drought-prone regions. Furthermore, strained water resources could lead to increased water costs that eventually affect the economic viability of production at scale.

Manufacturing sectors typically require a constant water supply. Historically, groundwater is a preferred source because of its relatively consistent water quality and ease of pretreatment. Similarly, most biofuel production facilities rely on groundwater for their water supply (Wu et al. 2009). Within an individual plant, the amount of water required annually for production is influenced by process technologies, plant design, system integration, and management schemes (Keeney and Muller 2006; Shapouri and Gallagher 2005). In recent years, extensive effort has been devoted to reducing water consumption by adoption of water-efficient technologies, reuse and recycle, and increased system integration in retrofitting existing plants (Mueller and Kwik 2013; POET 2011). New plants have begun to take into consideration the local water availability and quality, in addition to the logistics and economics of feedstock sourcing.

The development of the biofuel industry has been recorded through multiple industry surveys by various institutions. The U.S. Department of Energy's Bioenergy Technologies 
Office, within the Energy Efficiency and Renewable Energy Office, has tracked the capacity of cellulosic and advanced biofuels and hydrocarbons by surveying the production status of facilities at various RD\&D stages, from pilot to pre-commercial scales, annually. The latest report was issued in 2017 (Warner et al. 2017). For existing commercial-scale plants, several surveys have been conducted since 1998 (Shapouri and Gallagher 2005; Keeney and Muller 2006; Phillips et al. 2007; Wu 2008; Urbanchuk 2010; Mueller and Kwik 2013). These results indicated a remarkable improvement of efficiencies in energy and freshwater use during the period from 1998 to 2012 (Wu et al. 2009; Mueller and Kwik 2013). The Energy Resource Center at the University of Illinois at Chicago conducted a technology survey, focusing on advancement of technologies that increase yield and conserve energy while decreasing emissions (Mueller and Kwik 2013). The survey found that adoption of new technologies at production scale brought measurable benefits to areas ranging from process economics to environmental sustainability. Since then, industry-wide data compilation has been limited, although progress in individual plants has been reported elsewhere (POET 2011). New commercial-scale production facilities providing both cellulosic and conventional biofuels are on the rise (Biofuel International Magazine 2019). Because of continued emphasis on efficient design, advancement of technologies, and efforts to diversify product profiles through biorefining, and the number of retiring facilities that were replaced by newly designed plants in the last decade, the landscape of the biofuel industry is changing. We anticipate that production, energy, and environmental profiles have evolved in the last decade. Water use data collected previously from conventional and cellulosic ethanol production plants were limited to gallons of fresh water consumed per gallon of biofuel produced. Although the water usage rate is an important factor, it does not reveal the type of water resource, the fate of the water, where in the process water is used, or how wastewater is generated and managed. Consequently, it alone is insufficient to present the full picture of water resource use and management for a production facility. In addition, there is a lack of comprehensive estimation and analysis of water sourcing, management, treatment, and use at the unit operation stage; wastewater management; and the associated economics of current biofuel technologies for the industry. Therefore, it is necessary to document the progress of the biofuel industry and the status of its environmental sustainability.

With the support of the U.S. Department of Energy, Office of Energy Efficiency and Renewable Energy, Bioenergy Technologies Office, we conducted the present survey in 2018. The purpose of this study was to record the status of energy and water sustainability of the biofuel industry. The survey covers commercial-scale operations for biofuel production from corn grain via dry milling, corn kernel fiber, and soybeans at the facility level across the U.S.; it aims to be inclusive of all technologies for which data are available. A key purpose of this survey is to investigate and evaluate water resource use and wastewater management, to fill a gap in the industry survey. We acquired a range of parameters including type of water resource (both fresh and alternative), water use rate at the unit operation level, water reuse point, water treatment, cooling and boiler cycles of concentration, wastewater reuse and discharge methods, and cost. This report documents the findings of this survey. 


\section{METHODOLOGY}

Survey questionnaires for ethanol and biodiesel plants were developed separately in consultation with experts from the biofuel and water industries. The Renewable Fuels Association, National Biodiesel Board, and POET provided inputs to plant operation questions, and EcoLab Nalco provided inputs to water management questions for both ethanol plants and biodiesel plants. The survey contained 77 parameters in 22 categories. Survey forms were distributed in late spring through early summer of 2018. Responses were received in early fall through late November 2018. Responses to additional inquiries for clarification were received from individual facilities until late spring 2019. The survey aims to address 2017 commercialscale operation data. Reported values are based on un-denatured ethanol volumes.

Responses from the survey were analyzed for each parameter by plant capacity, feedstock, electricity and energy consumption, source and type of plant water, process water use, cooling and boiler system, yield, coproduct, and wastewater management. Statistical analysis was applied to calculate average, maximum, minimum, standard deviation, and quartiles at the $25^{\text {th }}$ percentile, median, and 75th percentile. Average values were weighted by biofuel production volume. Fractions of feedstock types, source of thermoenergy, source of electricity, source of water, and wastewater disposal methods were determined. Cooling and boiling water analysis was performed for the plants where data were available. Results of this survey were compared with those of previous surveys. Owing to limited responses from biodiesel plants, which accounted for less than $10 \%$ of the total production volume in 2017 , we were not able to develop a meaningful and statistically representative analysis of these plants. Thus, this report does not include the results from the biodiesel plant survey. 


\section{RESULTS}

A total of 65 dry-mill facilities responded to the survey, representing 55\% of top-ten producers and $33 \%$ of total production volume. Facility data were sorted, aggregated by category, and screened for outliers, and missing data were identified and followed up. Statistical analyses were applied to the datasets. Results are reported on the basis of plant capacity and startup year, feedstock, product and coproducts, energy use, and water use and management. This report uses the terms "biofuel" and "ethanol" interchangeably, because other types of commercial-scale biofuel production data were not sufficient to be representative.

\section{Production Capacity and Plant Start-up Year}

Respondents are distributed across 17 states (IL, IN, IA, KS, KY, MI, MN, MO, NE, NY, $\mathrm{ND}, \mathrm{OH}, \mathrm{SD}, \mathrm{TN}, \mathrm{TX}, \mathrm{VA}$, and WI), which include the 12 top fuel ethanol-producing Midwest states (Figure 1a). These plants contribute significant amounts of dry-mill-based biofuel production in the U.S. The actual U.S. production of fuel ethanol approached 16 billion gallons in 2017 (EIA 2018), which represented a 144\% increase over ten years (Table 1).

A majority of the respondents came online after 2001, with initial plant start-ups concentrated between 2003 and 2008 (Figure 1b). Newer plants gradually increased in number as older plants were retired. Fewer plants have been built since 2010. Figure 2a presents a histogram that provides a distribution of production capacity. The data reveal that medium- to small-size plants account for almost half of the total. The highest number of production plants are those producing around 60 million gallons per year (MGY), followed by 30 MGY. In 2017, these facilities produced 79 million gallons of biofuels per plant, on average. Statistically, the plant capacity expands from $57 \mathrm{MGY}$ at the 25th percentile to $75 \mathrm{MGY}$ at the median and 92 MGY at the 75th percentile, varying from as low as 34 MGY to as high as nearly $150 \mathrm{MGY}$ (Figure 2b). In 2017, a substantial portion of the plants were operated near maximum design capacity, $87 \%$ on average (Figure 3). This parameter has close distribution values of $82 \%$ at the 25th percentile, $89.5 \%$ at the median, and $93.5 \%$ at the 75 th percentile, with a small standard deviation (9.7\%). These data suggest that many facilities are near full capacity and that the possibility of large-scale production increases in existing facilities is somewhat limited. 


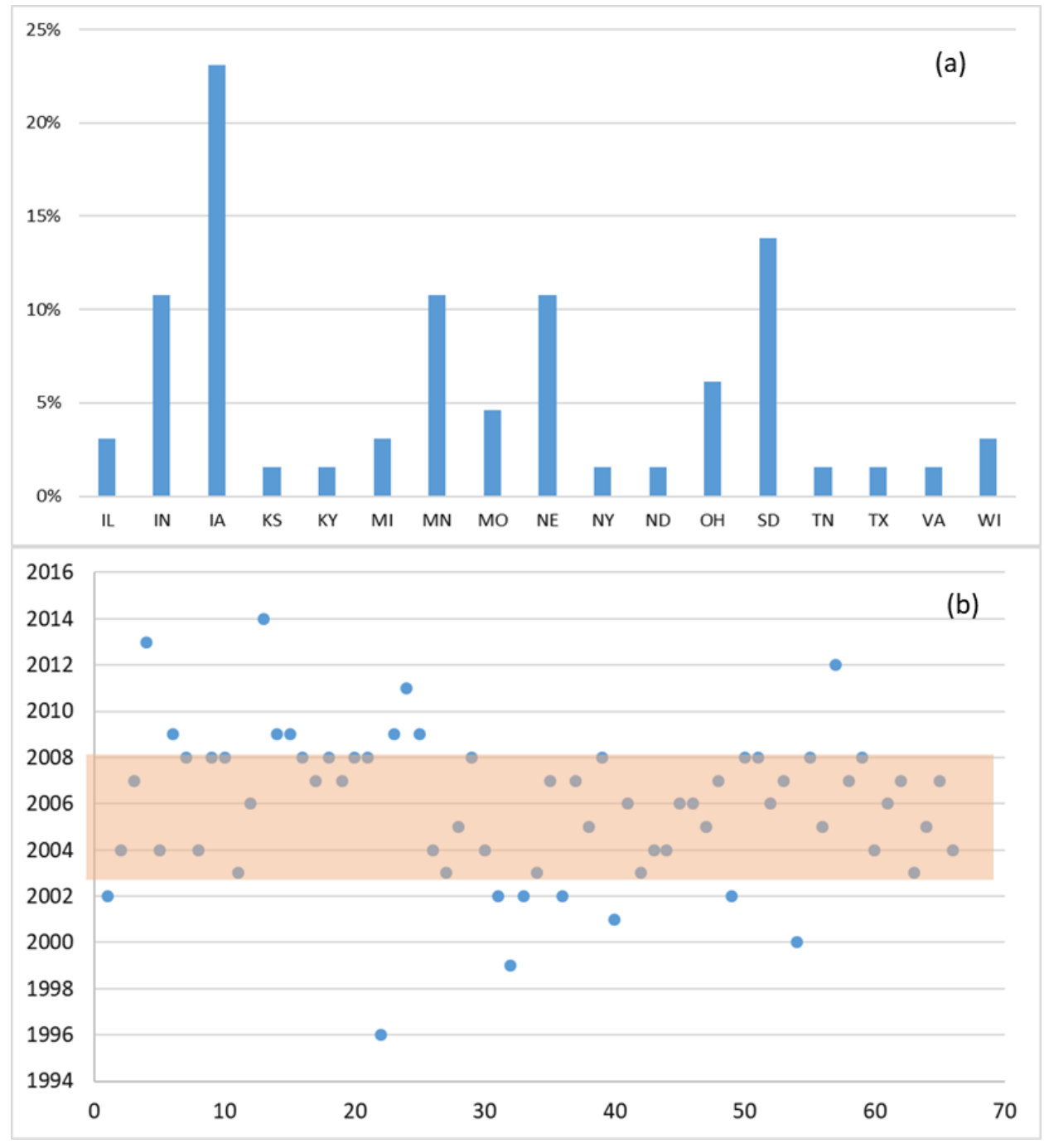

FIGURE 1 Distribution of dry-mill biofuel plants by (a) geographic regions and (b) start-up year. The numbers on the $\mathrm{x}$-axis in panel (b) are code numbers corresponding to specific plants (e.g., plant \#1 opened in 2002). The shaded area in panel (b) shows years with increased numbers of plant start-ups.

TABLE 1 Changes in ethanol production from dry mills from 2007 to 2017.

\begin{tabular}{lcc}
\hline & $\begin{array}{c}\text { Biofuel production (Million } \\
\text { gallons/year) }\end{array}$ & Increase from 2007 production (\%) \\
\hline 2007 & 6521 & \\
2008 & 9309 & $43 \%$ \\
2012 & 13218 & $103 \%$ \\
2017 & 15936 & $144 \%$ \\
\hline
\end{tabular}

Source of data: Renewable Fuels Association, n.d. 


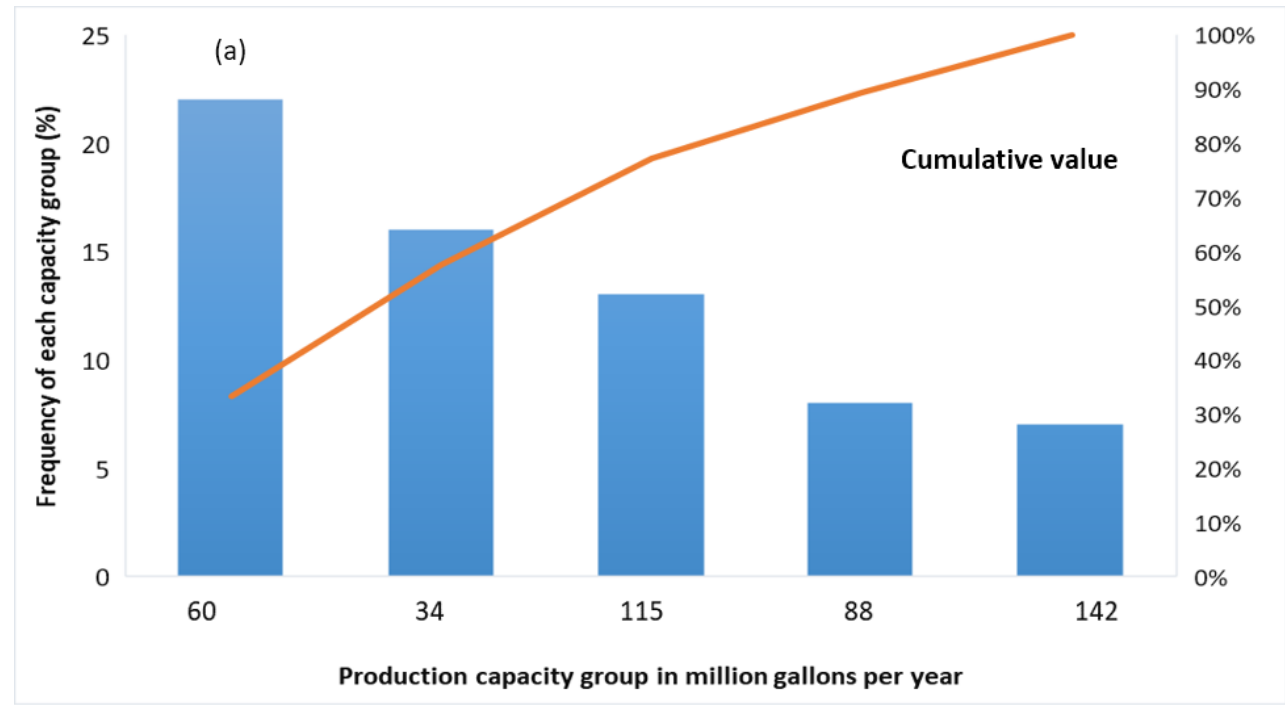

$160,000,000$

$140,000,000$

$120,000,000$

$100,000,000$

$80,000,000$

$60,000,000$

$40,000,000$

$20,000,000$

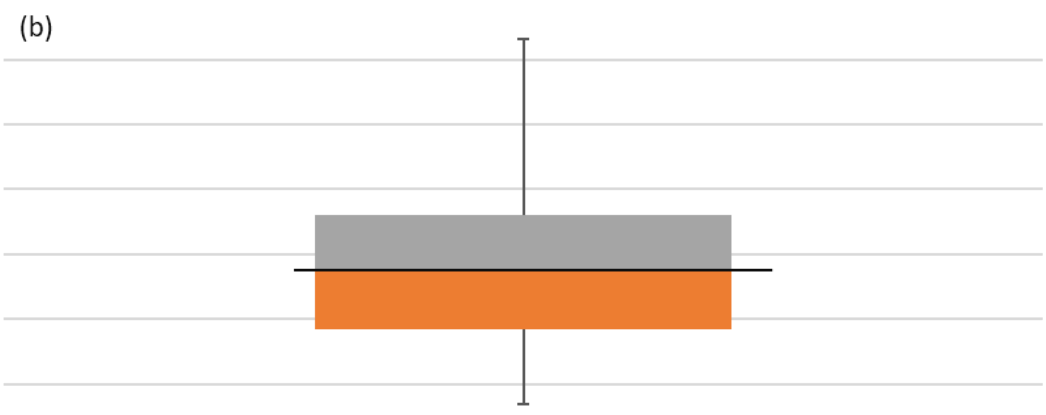

Production in million gallons per year

FIGURE 2 Ethanol production capacity. Panel (a) shows a histogram of production by capacity group; panel (b) presents results of statistical analysis of a minimum, 25th percentile, median, 75th percentile, and maximum production capacity dataset. The centerline inside the boxes represents the median value. The top of the gray box displays the 75th percentile, and the bottom of the orange box displays the 25th percentile. The maximum and minimum values are displayed with vertical lines ("whiskers") connecting the points to the center boxes. 
$120 \%$

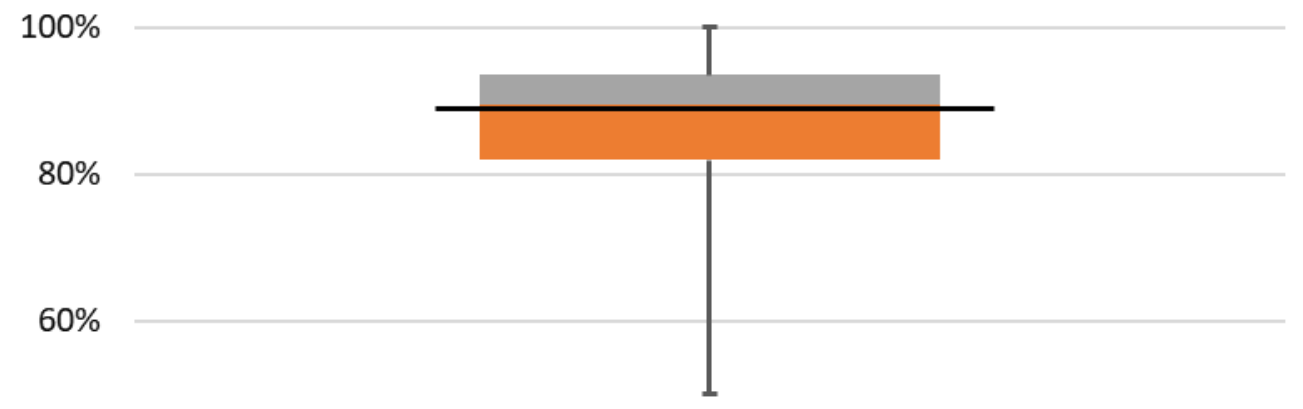

$40 \%$

$20 \%$

\section{Maximum Operation Capacity Used}

$0 \%$

FIGURE 3 Production capacity under operation in 2017 compared to maximum design capacity. The centerline inside the boxes represents the median value. The top of the gray box displays the 75th percentile, and the bottom of the orange box displays the 25 th percentile. The maximum and minimum values are displayed with vertical lines ("whiskers") connecting the points to the center boxes.

\section{Feedstock Sources}

Corn grain stood out as the dominant feedstock for bioethanol in 2017 (Figure 4). Grain sorghum remained at $1 \%$ of feedstock. The survey reveals that corn kernel fiber is entering the market. In conventional grain-starch fermentation, corn kernel fiber ended up in distiller's dried grains with solubles (DDGS). The cellulosic material has now become a feedstock for cellulosic ethanol production, although at a small fraction (1\%). In this survey, 27 plants reported producing ethanol from corn fiber, accounted for $41 \%$ of respondents. Considering 200 plants in operation for the industry (RFA 2019) in 2017, the corn fiber ethanol facilities would be about $14 \%$ of the ethanol plants nationwide. Recently, the California Air Resource Board approved two biorefineries that carry out the fermentation process using corn kernel fiber (Biofuel International Magazine, 2019). The two plants, with a total capacity of $240 \mathrm{MGY}$, are expected to produce corn kernel fiber ethanol at a level of $3 \%$ of total production.

Survey data show diversified feedstock sourcing. The extent of sourcing in a given state is largely affected by production scale in that state. At the aggregated state level, biorefineries in Iowa, South Dakota, Illinois, and Indiana obtained feedstock from at least four states and up to eight states (Table 2). On average, plants sourced their feedstock from three states. Because of costs associated with feedstock transport, plants tend to source a majority of feedstock in their 
own state, as evidenced by the diagonal distribution of the longest bars in Table 2. Most feedstock providers are from the Midwest.

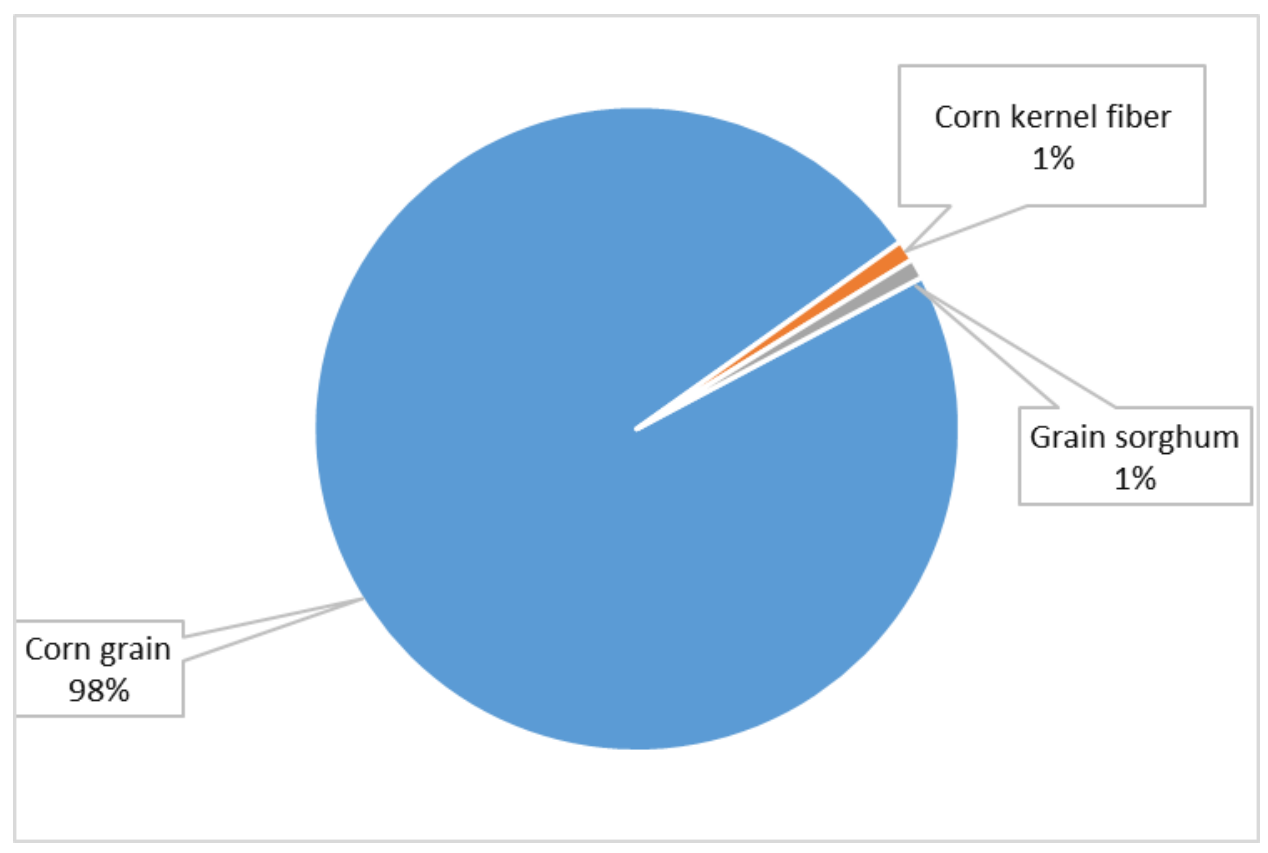

FIGURE 4 Feedstock of dry-mill ethanol-producing facilities.

TABLE 2 Source of feedstock supply to biorefineries by state. Bar length represents relative proportion of feedstock from each state (column) that is sourced to the biorefineries (row) in that state.

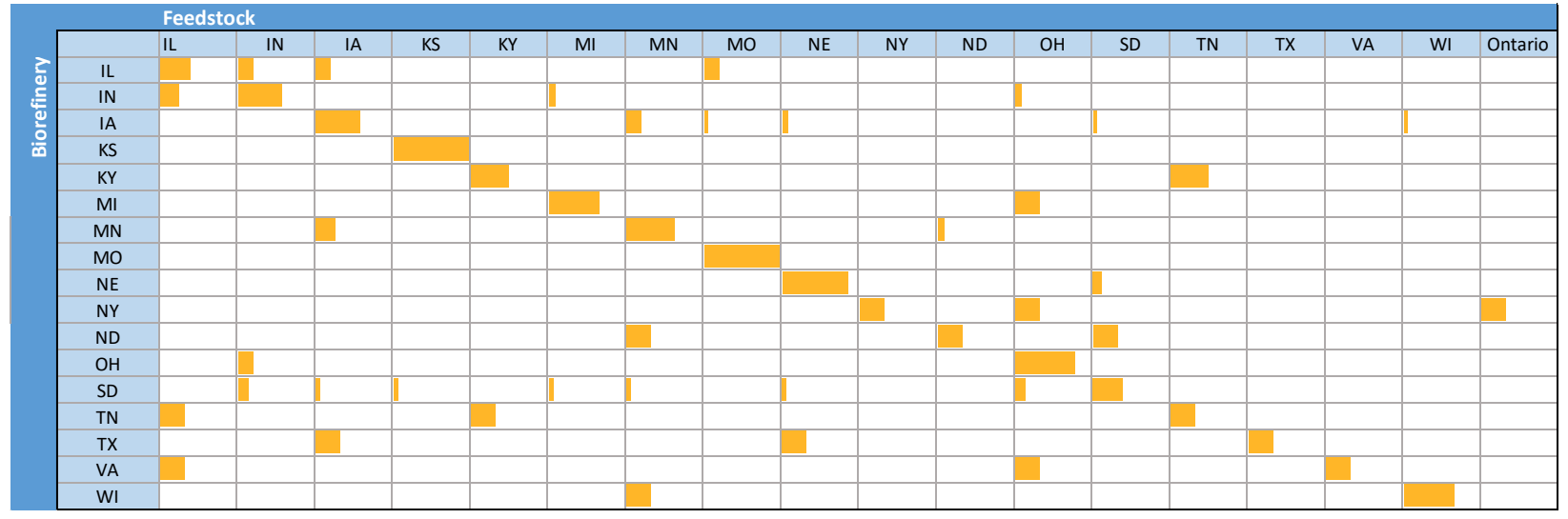




\section{Product Portfolio and Yields}

Ethanol-plant product portfolios are increasingly diversified. Advancement of conversion technologies is also reflected in the data. The survey found that simultaneous (in situ) coprocessing of starch and cellulosic feedstock was widely adopted in those plants that were producing ethanol from both corn kernel fiber and grain. In the conventional conversion process, kernel fibers would bypass fermentation and end up in DDGS. With the new process, the fibers are converted to ethanol via fermentation. The net result is a shift of DDGS composition toward increased protein content, which increases the nutritional value of DDGS. This process enables cellulosic ethanol production from corn kernel fiber at existing ethanol plants without the need for significant upgrades or additional capital expenditures. On average, 2.81 gallons of bioethanol is produced from a bushel of corn in a traditional grain-starch fermentation process. When simultaneous co-processing is introduced, ethanol yield increases to 2.88 gallons per bushel (Figure 5). Evidence suggests that some or all of this $2.5 \%$ increase in biofuel production is attributed to corn kernel fiber, which accounts for only $1 \%$ of total feedstock (Figure 4). Figure 5 presents results of statistical analysis of the yield: maximum, 75th percentile, median, 25th percentile, and minimum values for the conventional grain fermentation and grain/fiber coprocessing reported in this survey.

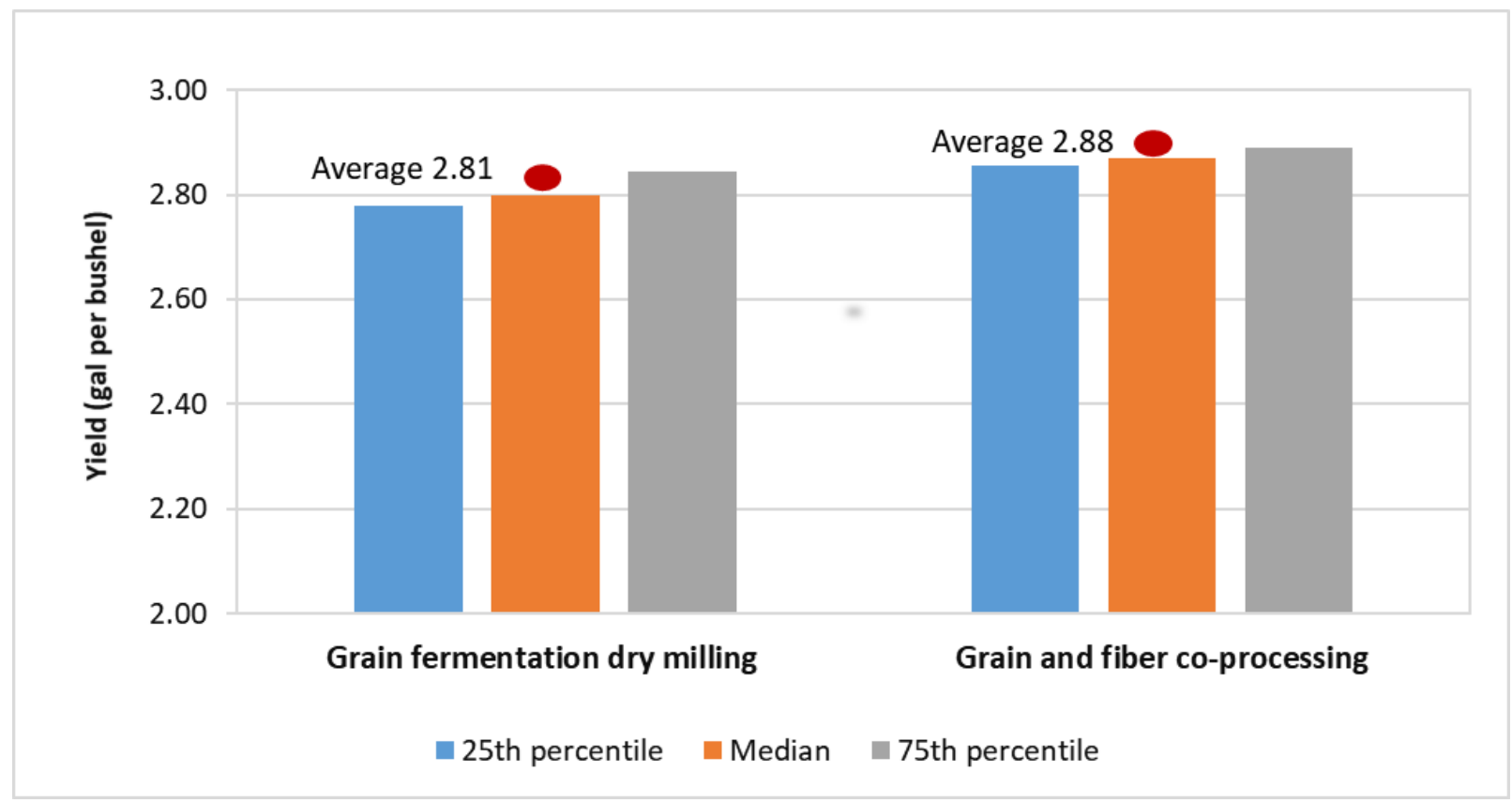

FIGURE 5 Maximum, 75th percentile, median, 25th percentile, and minimum values of biofuel yield derived from grain fermentation and from grain and corn kernel fiber co-processing.

The list of coproducts from dry mills has been expanded in recent years. Corn oil separation is available in all the facilities. On average, 0.041 gallon of corn oil is produced per gallon of ethanol. Plants produced a diverse group of DGS products. Typically, $5.3 \mathrm{lbs}$ of DGS are generated for each gallon of ethanol produced. A plant operator may decide to produce a range of the above coproducts, or only a few. The survey found that a majority of plants are also producing DDGS, wet distillers grain (WDG), modified wet distillers grain (MWDG), syrup, and 
$\mathrm{CO}_{2}$ gas. For the plants that produce varying degrees of the coproducts, it is estimated that $4.5 \mathrm{lb}$ of DDGS, $2.4 \mathrm{lb}$ of WDG, $0.86 \mathrm{lb}$ of MWDG, $0.17 \mathrm{lb}$ of syrup, and $2.4 \mathrm{lb}$ of $\mathrm{CO}_{2}$ gas are produced per gallon of ethanol on average. Note that the moisture levels of each of the DGS products are very different, ranging from $10 \%$ to $13 \%$ in DDGS, $42 \%$ to $55 \%$ in MWDG, $50 \%$ to $58 \%$ in WDG, and $62 \%$ to $79 \%$ in syrup. In terms of coproduct distribution, nearly all the plants surveyed produce corn oil and DDGS; a majority produce WDGS; and approximately half produce syrup. MWDG and $\mathrm{CO}_{2}$ are among the least produced coproducts. Many plants expressed an interest to increase production of MWDG. As depicted in Figure 6, the distribution (25th percentile, median, and 75th percentile) of the yield of these coproducts is relatively narrow. There are, however, extreme cases in the maximum values for DDGS and WDGS. $\mathrm{CO}_{2}$ generated from the fermentation process in ethanol plants is a high-grade stream with $99.9 \%$ purity, which can become an additional value stream. After minor processing to remove impurities, this stream is sourced for manufacturing of food and beverages, and is highly sought by other industries, particularly the petroleum industry, which uses it for $\mathrm{CO}_{2}$-EOR (enhanced oil recovery). Together, the $\mathrm{CO}_{2}$ from ethanol plants made up about $40 \%$ of the North American merchant market in 2017. $\mathrm{CO}_{2}$ extraction and storage is on the rise; in one case (an ADM corn processing plant), 1,000 MT per day of $\mathrm{CO}_{2}$ was captured from ethanol fermentation and injected into a saline reservoir, where 1 million MT was stored over three years (State $\mathrm{CO}_{2}$-EOR Deployment Work Group, 2017). In the present survey, we found that $14 \%$ of the facilities extracted a $\mathrm{CO}_{2}$ stream.

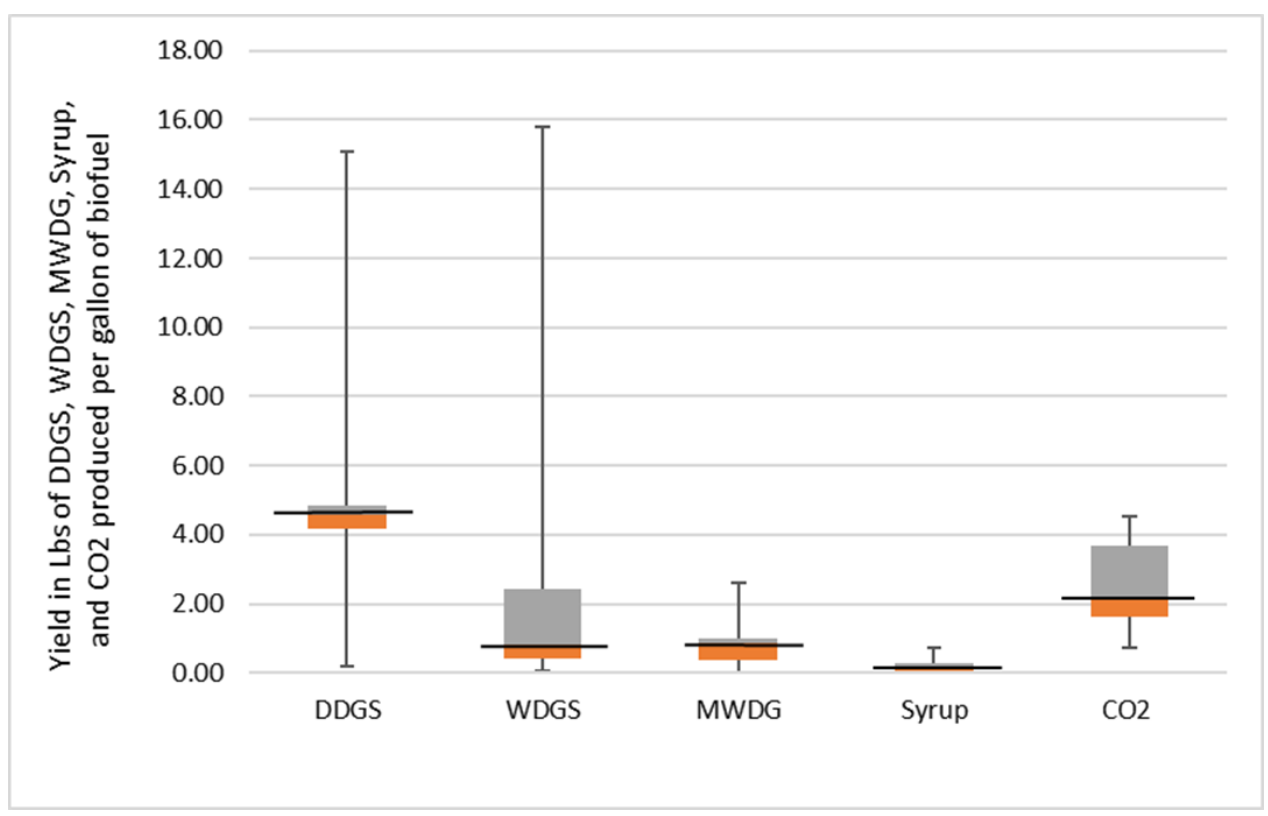

FIGURE 6 Yields of coproducts DDGS, WDGS, MWDG, syrup, and $\mathrm{CO}_{2}$ gas. The graph depicts maximum, 75th percentile, median, 25th percentile, and minimum values. The centerline inside the boxes represents the median value. The tops of the gray boxes display the 75th percentile, and the bottoms of the orange boxes display the 25 th percentile. The maximum and minimum values are displayed with vertical lines ("whiskers") connecting the points to the center boxes. 


\section{Fuel and Electricity Use}

Natural gas is the dominant fuel source, providing thermal energy for $98 \%$ of ethanol production. Other fuel sources including coal, biomass, and landfill gas account for $1.6 \%$ of total production (Figure 7). In terms of numbers of facilities, coal, biomass, and landfill gas-based plants make up $4.6 \%$ of the total. Data show that ethanol plants are aggregated in

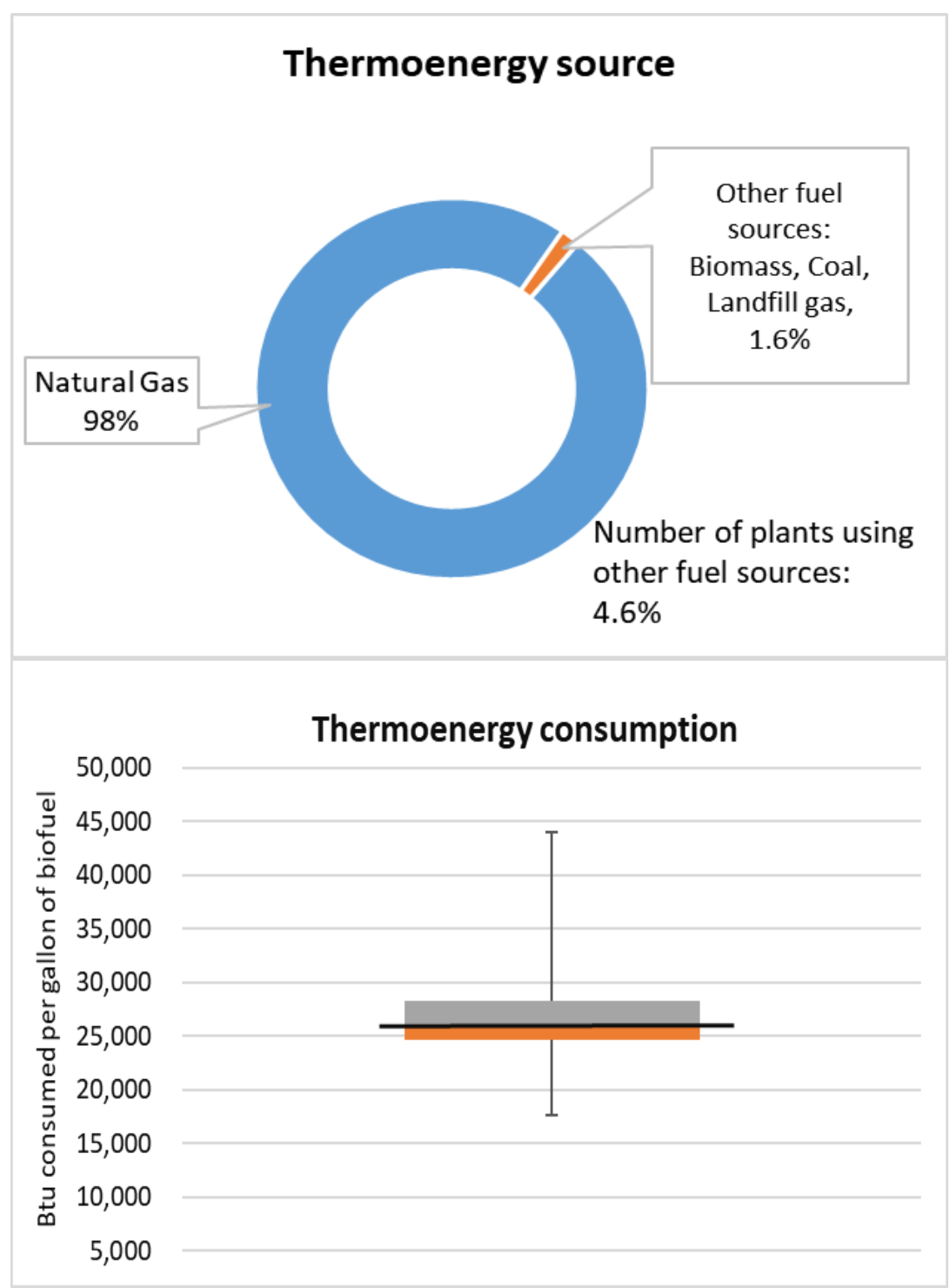

FIGURE 7 Source of thermoenergy and maximum, 75th percentile, median, 25th percentile, and minimum values of thermoenergy consumption. The centerline inside the boxes represents the median value. The top of the gray box displays the 75 th percentile, and the bottom of the orange box displays the 25 th percentile. The maximum and minimum values are displayed with vertical lines ("whiskers") connecting the points to the center boxes. 
a narrow band between 24,664 Btu/gal and 28,209 Btu/gal (Figure 7), with a median value of $25,820 \mathrm{Btu} / \mathrm{gal}$. The most energy-efficient plant consumes 17,670 Btu per gallon, while the least efficient one requires 43,985 Btu per gallon. As older plants are gradually retired and plants are operated in design capacity, we expect to see lower average energy consumption.

Grid electricity supplied $95 \%$ of the production need in 2017 . The remaining $5 \%$ of electricity was provided through on-site generation (Figure 8). Although it represents a small fraction of the total, on-site electricity generation tended to use various renewable sources, instead of using fossil. In one case, hydropower provided $90 \%$ of the electricity used. Increased on-site generation thus represents a replacement of fossil energy by renewable energy. On average, facilities used $0.747 \mathrm{kWh}$ of electricity to produce a gallon of ethanol. As seen in Figure 9, electricity usage rates in the plants surveyed were very similar, with a distribution from the 25 th percentile $(0.61 \mathrm{kWh} / \mathrm{gal})$ to the 75 th percentile $(0.91 \mathrm{kWh} / \mathrm{gal})$. The lower percentile and minimum value represent plants that had on-site generation capability. Electricity consumption for ethanol and DGS production both have narrow distributions, from the $25^{\text {th }}$ percentile to the $75^{\text {th }}$ percentile. These values suggest stable operation parameters in a mature process. In contrast, the distribution of $\mathrm{CO}_{2}$ in $\mathrm{kWh} / \mathrm{gal}$ is relatively wide, largely because of extensive variation in $\mathrm{CO}_{2}$ extraction level that the per-gallon metric does not reflect. We further analyzed total electricity consumption, on-site generation, and grid inputs. Results demonstrated positive savings on grid electricity by quite a few plants (Figure 10). In several instances, electricity generated on-site was able to completely replace electricity from the grid and even provide excess kilowatt-hours, such that the plant became a net electricity exporter.

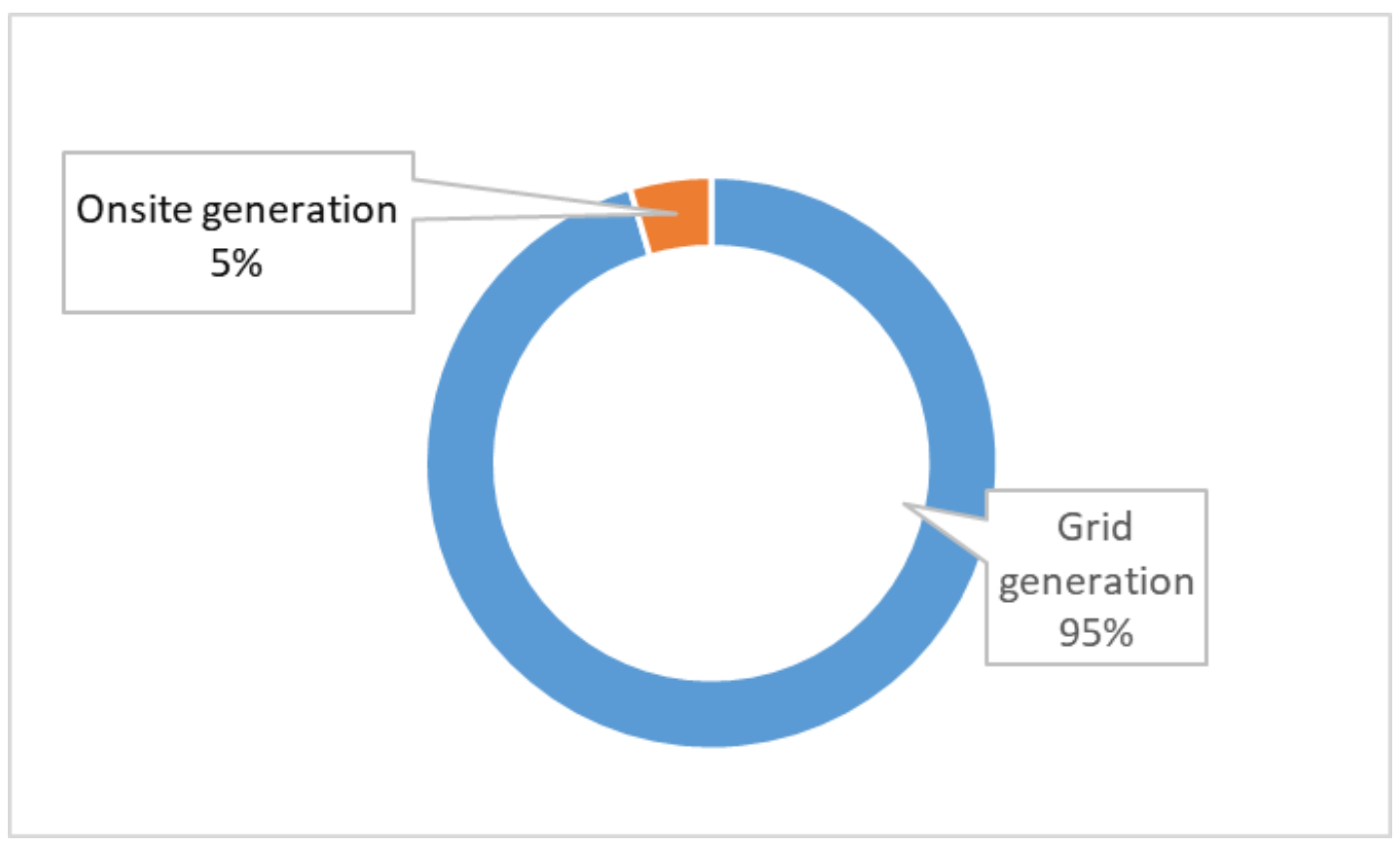

FIGURE 8 Source of electricity in dry-mill ethanol plants. 


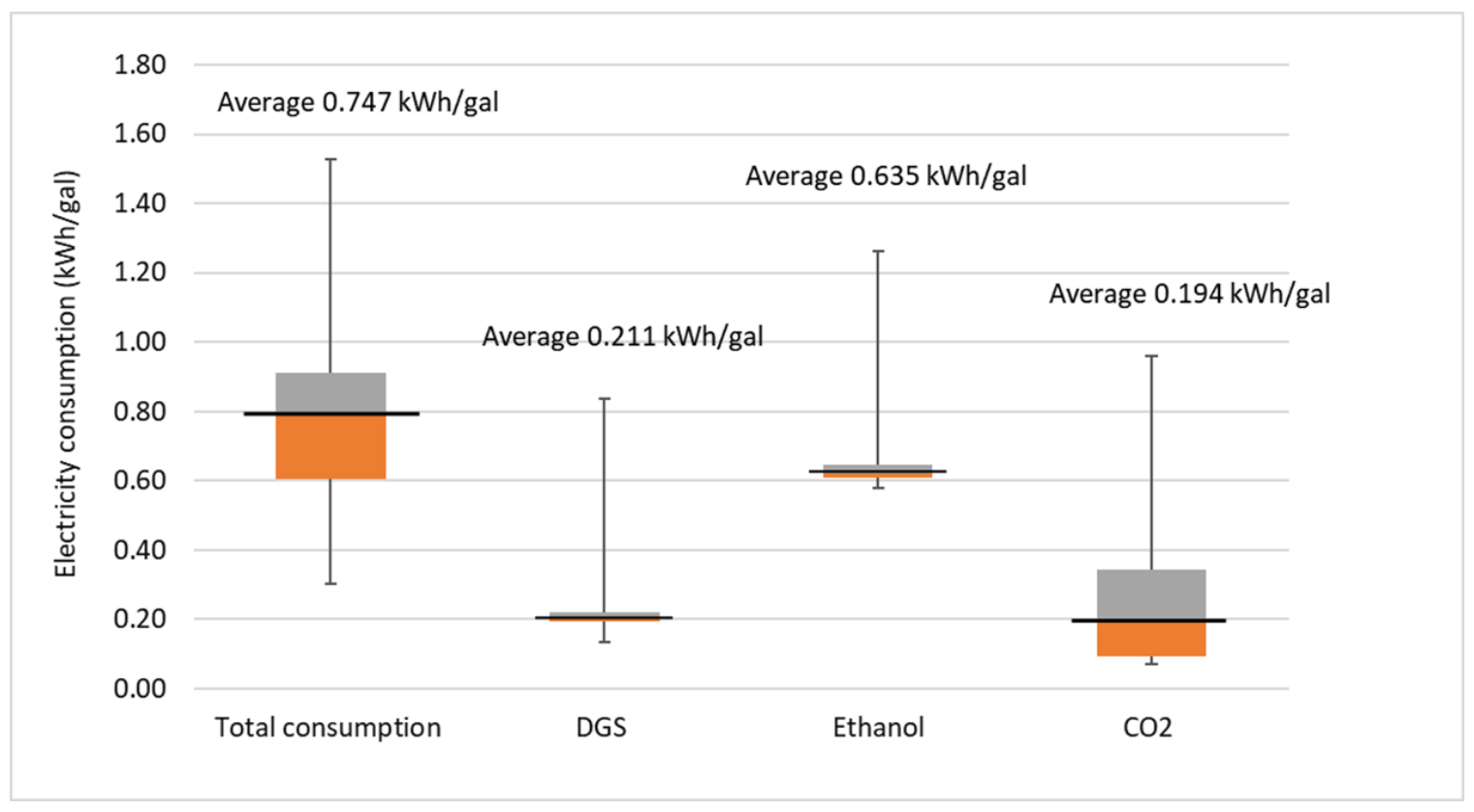

FIGURE 9 Statistical analysis of electricity consumption in ethanol plants (total consumption, and individual operation steps of the plants that produce specific products): maximum, 75th percentile, median, 25th percentile, and minimum values. The centerline inside the boxes represents the median value. The top of the gray box displays the 75th percentile, and the bottom of the orange box displays the 25 th percentile. The maximum and minimum values are displayed with vertical lines ("whiskers") connecting the points to the center boxes.

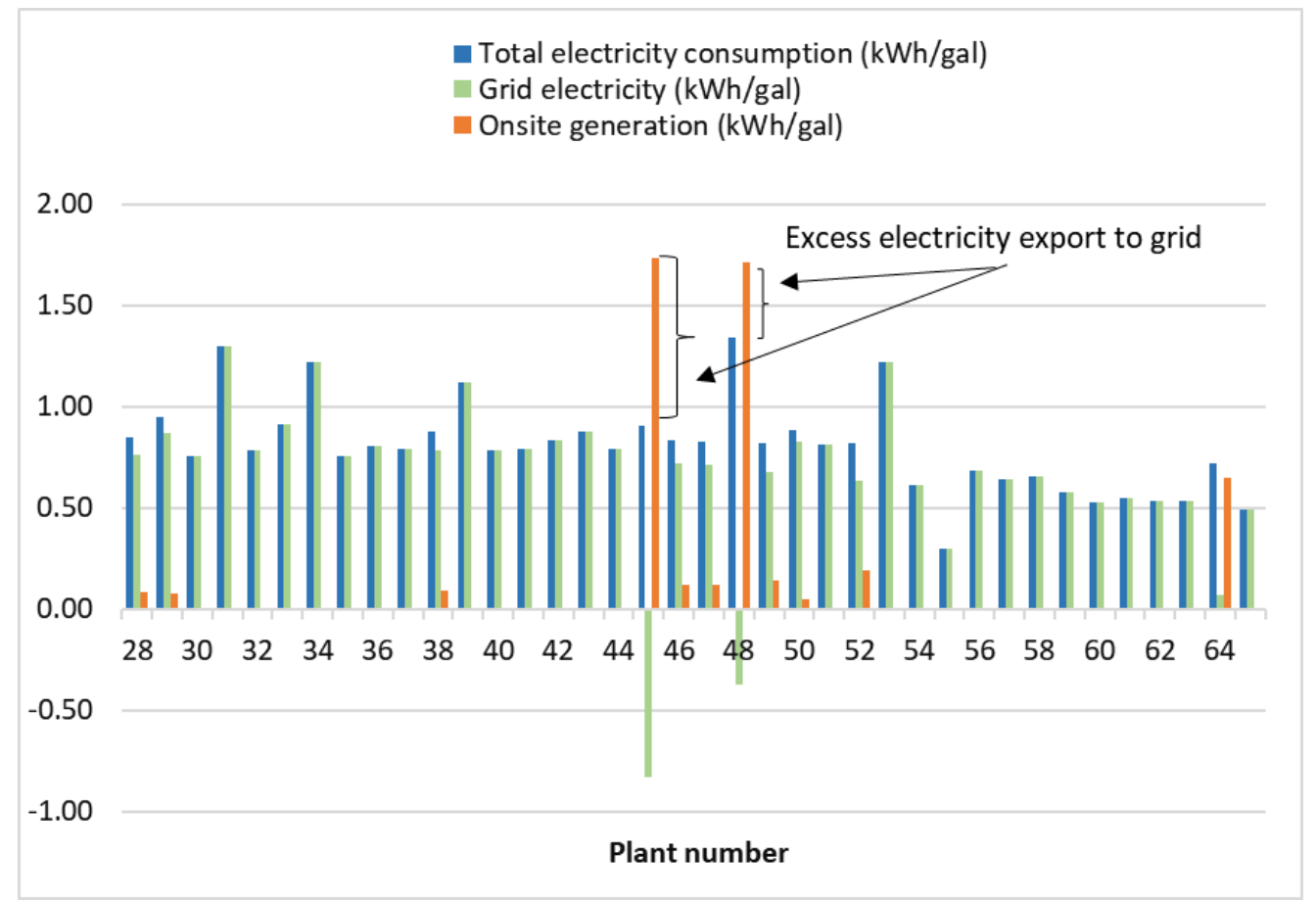

FIGURE 10 Electricity demand, grid electricity use, and displacement by on-site generation in example facilities. 
While on-site generation saves demand for grid electricity, diversifying the product portfolio by exporting $\mathrm{CO}_{2}$ may increase total demand. On the basis of survey data, it takes 0.194 $\mathrm{kWh} / \mathrm{gal}$ to compress the $\mathrm{CO}_{2}$ gas stream in the plants (Figure 9). This amount accounts for $19 \%$ of total electricity use in the plants that are extracting $\mathrm{CO}_{2}$ (Figure 11). For these plants, extracting $\mathrm{CO}_{2}$ means additional electricity demand. Survey data showed that those plants producing both ethanol and $\mathrm{CO}_{2}$, which accounted for about $14 \%$ of the surveyed plants, contributed mostly to the high end of electricity usage. If $\mathrm{CO}_{2}$ export from ethanol plants as a revenue-added product is increased, electricity usage may increase. Conversely, if a plant with on-site electricity generation capacity from a non-fossil fuel source is located in a region in which the electricity mix contains a large fraction of fossil fuel, and the plant is capable of using the excess electricity to extract $\mathrm{CO}_{2}$, the benefits will be twofold. In this case, the plant not only reduces its greenhouse gas emissions from a life-cycle perspective because of reduced grid electricity demand, but also provides biogenic $\mathrm{CO}_{2}$ to support other manufacturing process in a circular economy.

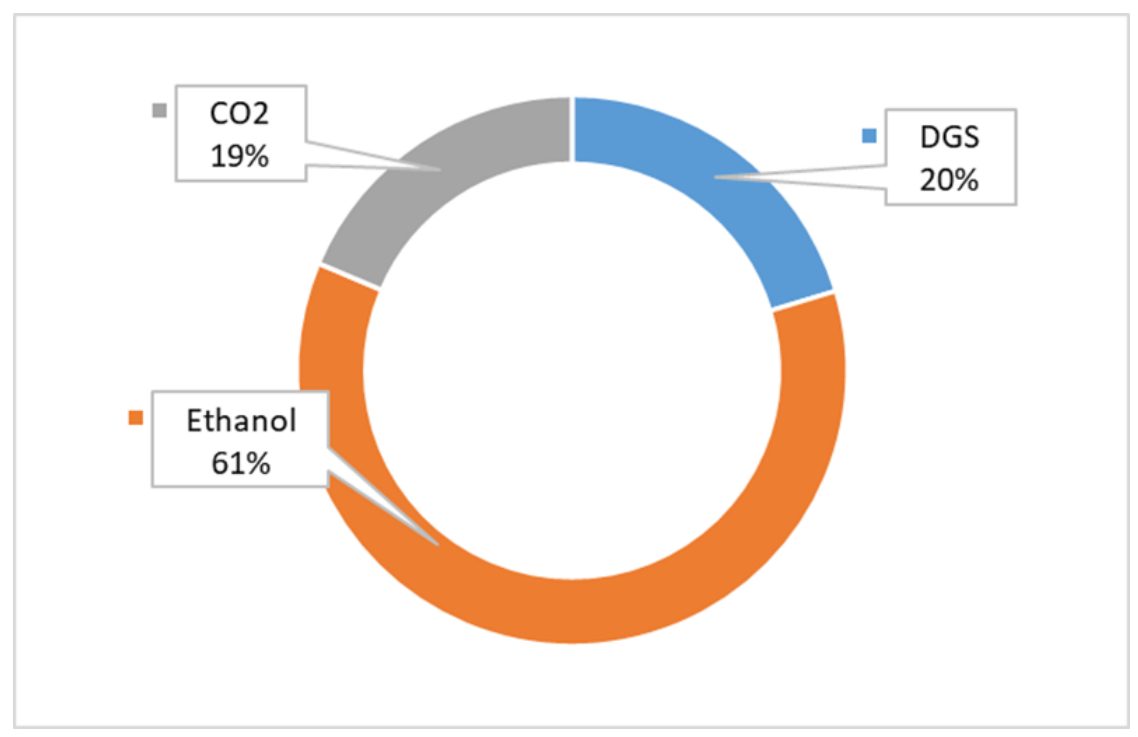

FIGURE 11 Electricity consumption based on product for ethanol plants that export $\mathrm{CO}_{2}$.

Cooling system operation requires substantial electricity inputs. Available data demonstrate that it takes from $0.06 \mathrm{kWh}$ to $0.11 \mathrm{kWh}$ to circulate a gallon of cooling water, with an average of $0.08 \mathrm{kWh}$ (Figure 12). Almost all of the respondents operate recirculating cooling towers. The types of cooling tower and pump motor/fan drive the electricity demand. Newer plants with energy-efficient cooling system designs exhibit lower energy consumption, while other factors such as elevated ambient temperature would increase energy demand. 


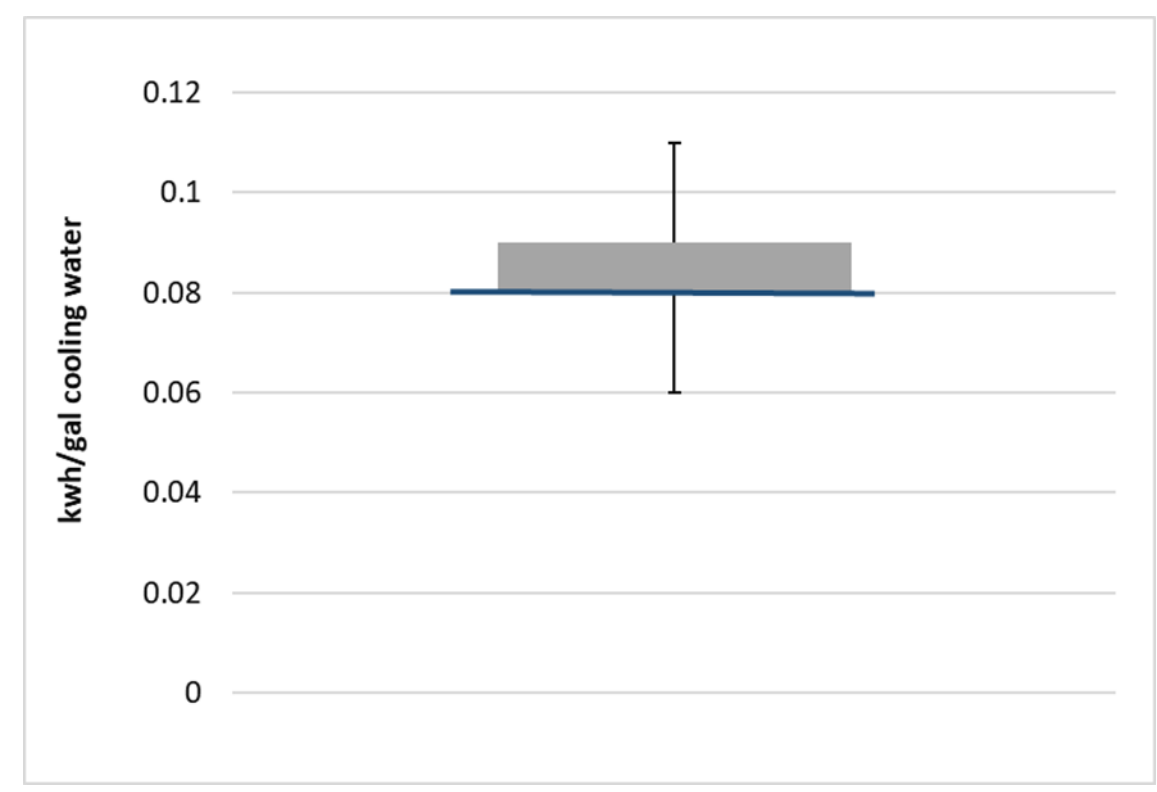

FIGURE 12 Cooling system energy usage: maximum, 75th percentile, median, 25th percentile, and minimum value of electricity requirement. The horizontal line represents the median value. The top of the gray box displays the 75 th percentile, and the 25 th percentile overlaps with the median. The maximum and minimum values are displayed with vertical lines ("whiskers") connecting the points to the center box.

\section{Energy and Water Use in Distillers Grain Processing}

A key step in coproduct processing is drying, which requires substantial amounts of energy input. Ethanol plants have developed wet products to limit their energy costs. Of the total plant thermo-energy (natural gas) use in plants equipped with a natural-gas drying process, $31 \%$ contributes to drying DDG, and the remaining $69 \%$ to biofuel production. Similarly, drying coproducts takes a quarter of plant electricity use, on average, in plants with an electric drying process and without $\mathrm{CO}_{2}$ compression (Figure 13). Reducing drying needs by producing WDG and MWDG, which is a mixture of DDGS and WDG, thus means significant energy savings. As shown in Figure 14, the coproducts DDGS, WDGS, MWDG, and syrup have moisture contents ranging from $10 \%$ to $70 \%$. Instead of drying the WDG from about $60 \%$ moisture to $12 \%$ as DDGS, driving out the moisture from WDG to produce MWDG (which contains approximately $50 \%$ moisture) only requires a fraction of the energy overall. In practice, the MWDG is often produced by blending WDG with DDGS. If energy saving is prioritized and MWDG market is growing, the number of plants that produce MWDG is expected to increase in the near future. 


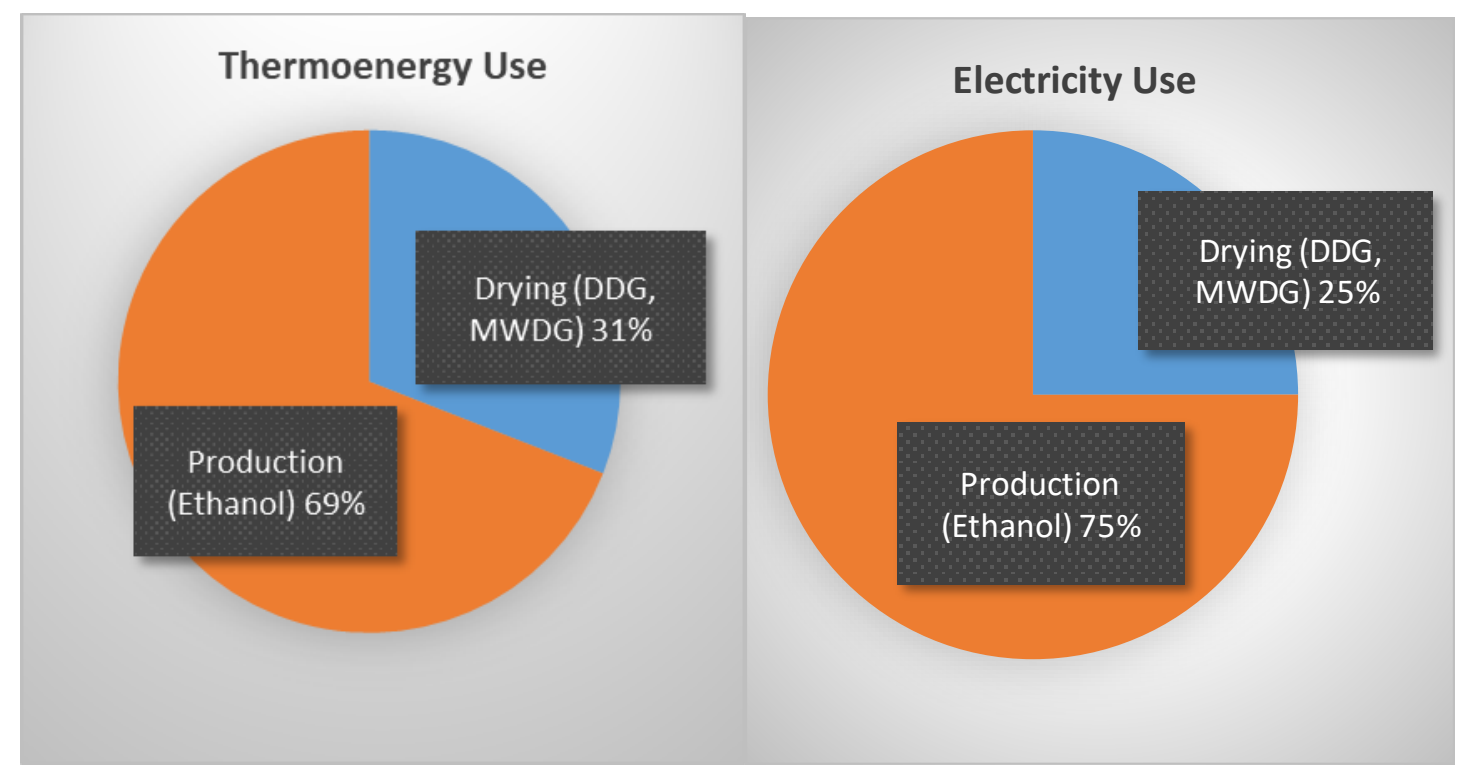

FIGURE 13 Electricity and thermoenergy (primarily natural gas) used for ethanol production and coproducts drying per gallon of biofuel produced.

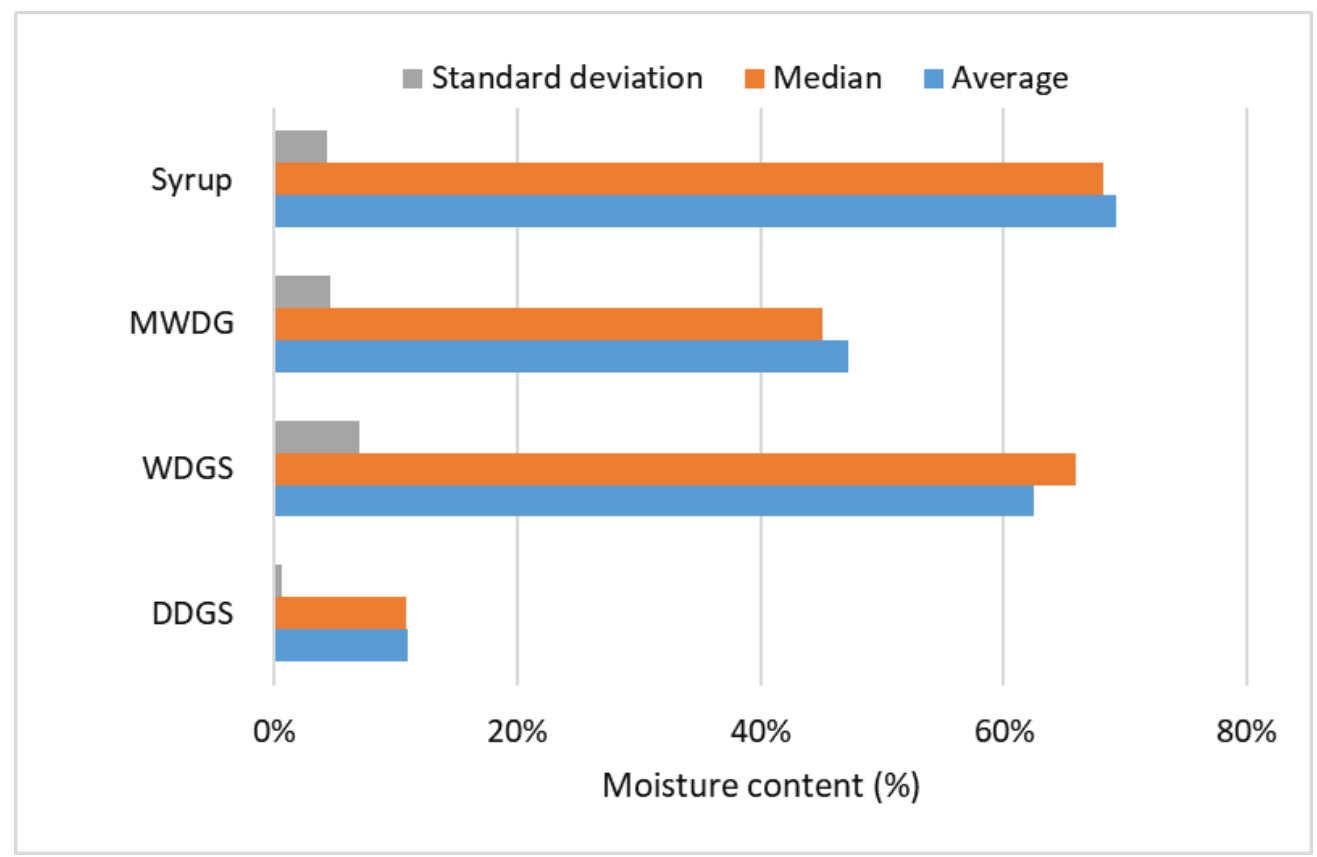

FIGURE 14 Moisture content of coproducts DDGS, WDGS, MWDG, and syrup. 
In the past, steam or natural-gas dryers were used for coproduct drying. Steam generation requires both energy and water input to the boiler. In this survey, we found that a majority of plants use a natural-gas-fired dryer or an electric dryer. Switching from steam to natural gas or electricity in the drying process reduces needs for fresh water and water treatments, and thus represents a reduction in not only the water footprint but also the operation cost.

Drying coproducts such as DDGS entails a significant water loss through evaporation (Wu et al. 2018). However, if we consider the fate of water, water in wet products such as WDGS and MDGS is used by animals to help meet their dietary water requirement. Therefore, water loss through sale of WDGS and MWDG to animal feedlots would be considered water reuse in the agriculture sector. From the energy use and water management viewpoint, export of wet coproducts is highly encouraged because of environmental sustainability considerations for both energy and water.

\section{Water Resources and Water Intensity}

This is the first survey that records comprehensive water resource use, water consumption rate, recycling, cost, and wastewater management for the U.S. biofuel industry. Results provide data needed to assess the progress and impact on environmental sustainability in the context of the FEW nexus. The survey found diverse water resource use in dry-mill ethanol plants. More than half of the facilities source water from wells (groundwater, Figure 15). Less than $40 \%$ use a city water supply. Surface streams are used by $7 \%$ of facilities. Alternative water resource use is on the rise: power plant cooling water discharge and reclaimed municipal wastewater are used by $3 \%$ of production facilities. If calculated by production volume, groundwater use increases from $51 \%$ to $60 \%$ because larger plants tend to use groundwater. Fractions of ethanol produced using city water and surface water vary slightly, and alternative water use remains at 3\% (Figure 16). Production facilities may adopt alternative water resources: effluent from wastewater treatment plants, water sources from quarries, and cooling ponds of a power plant have been reported (POET 2011). One production facility sources 80 percent of its water from the cooling ponds of an adjacent power plant and discharges it back to the power plant. Water resource demands by manufacturing facilities add stress to local water resource availability. Continued increases in alternative water use will further drive down freshwater demand in existing plants. This approach relieves water stress in drought-prone areas, or makes additional water available to other sectors in resource-rich areas. Overall, it improves water resource sustainability in the region. However, switching to alternative water resources requires investment and highly depends on priorities. Although plants that already use alternative water resources will continue their practices, the rest of the respondents have no plans to switch current freshwater resources to alternative sources during the next five years. 


\section{Water source use by number of facilities}

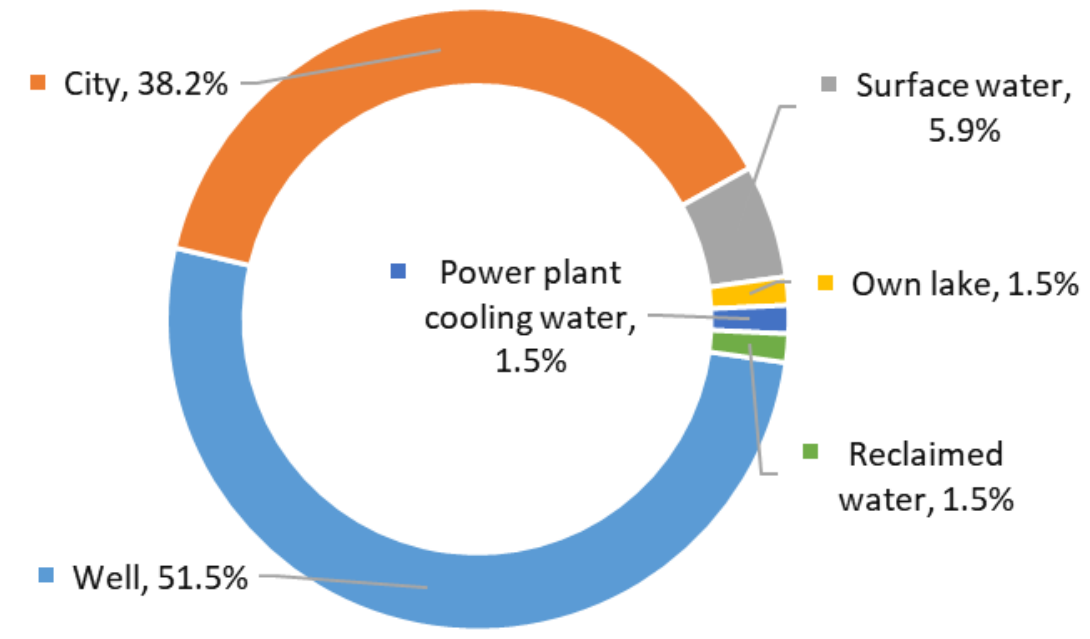

FIGURE 15 Types of water resources used in biofuel production, by number of facilities.

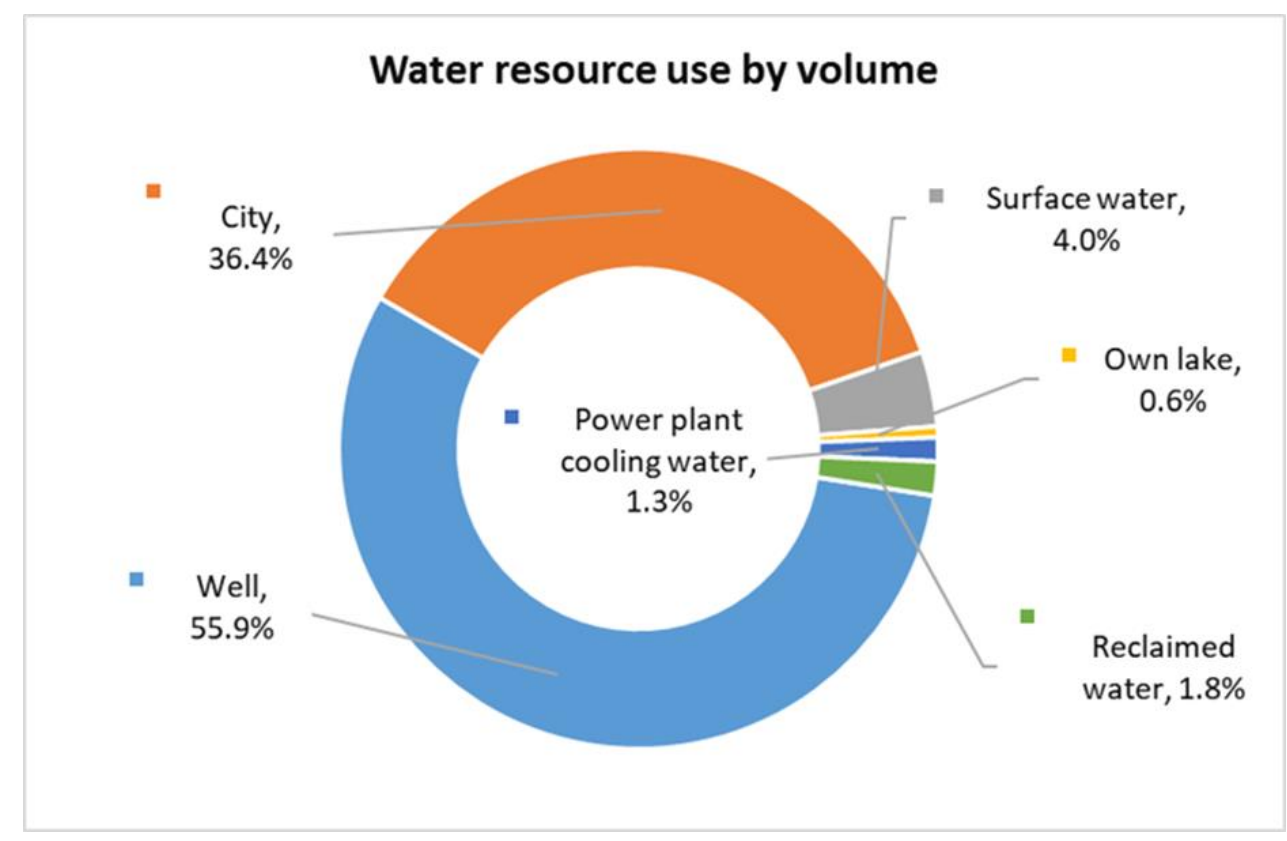

FIGURE 16 Types of water resources used in biofuel production, by production volume. 
It took 2.65 gallons of freshwater, on average, to produce a gallon of ethanol in 2017. The industry has sourced reclaimed water and cooling blowdown in the production, which accounts for $3.1 \%$ of total water use volume. Combining freshwater and alternative water use, total water consumption is $2.74 \mathrm{gal} / \mathrm{gal}$, which means 0.09 gallons of freshwater would be used in the production were saved for every gallon of ethanol produced. Figure 17 shows that the total water use data mostly merge to a close band of 2.43-3.00 gal/gal (from the 25 th to $75^{\text {th }}$ percentile). In 2008, the industry used an average of three gallons of freshwater per gallon of ethanol, which was a $48 \%$ decrease from ten years previously (5.8 gal/gal, Wu et al. 2009). In a 2012 survey, this figure decreased to $2.90 \mathrm{gal} / \mathrm{gal}$. By 2017, an additional 0.35 gallons of freshwater use was being avoided per gallon of ethanol, which accounts for $12 \%$ of water savings relative to 2008 . From 1998 to 2017, the industry was able to lower the freshwater requirement by $54 \%$, a significant decrease in 19 years. The reduction of the water consumption rate resulted from conservation management and practices in plants and improved engineering design. In individual facilities, total water use averaged $252 \mathrm{MGY}$, with a median value of 178 million gallons (Figure 17). The higher average value relative to the median suggests that more plants are above 200 million gallons than below. A majority of plants (25th to 75 th percentile) fall into the range of 148 million to 272 million gallons. These are water demands on local water resources. The impact of production on regional water availability is highly variable, depending on the abundance of regional water resources.

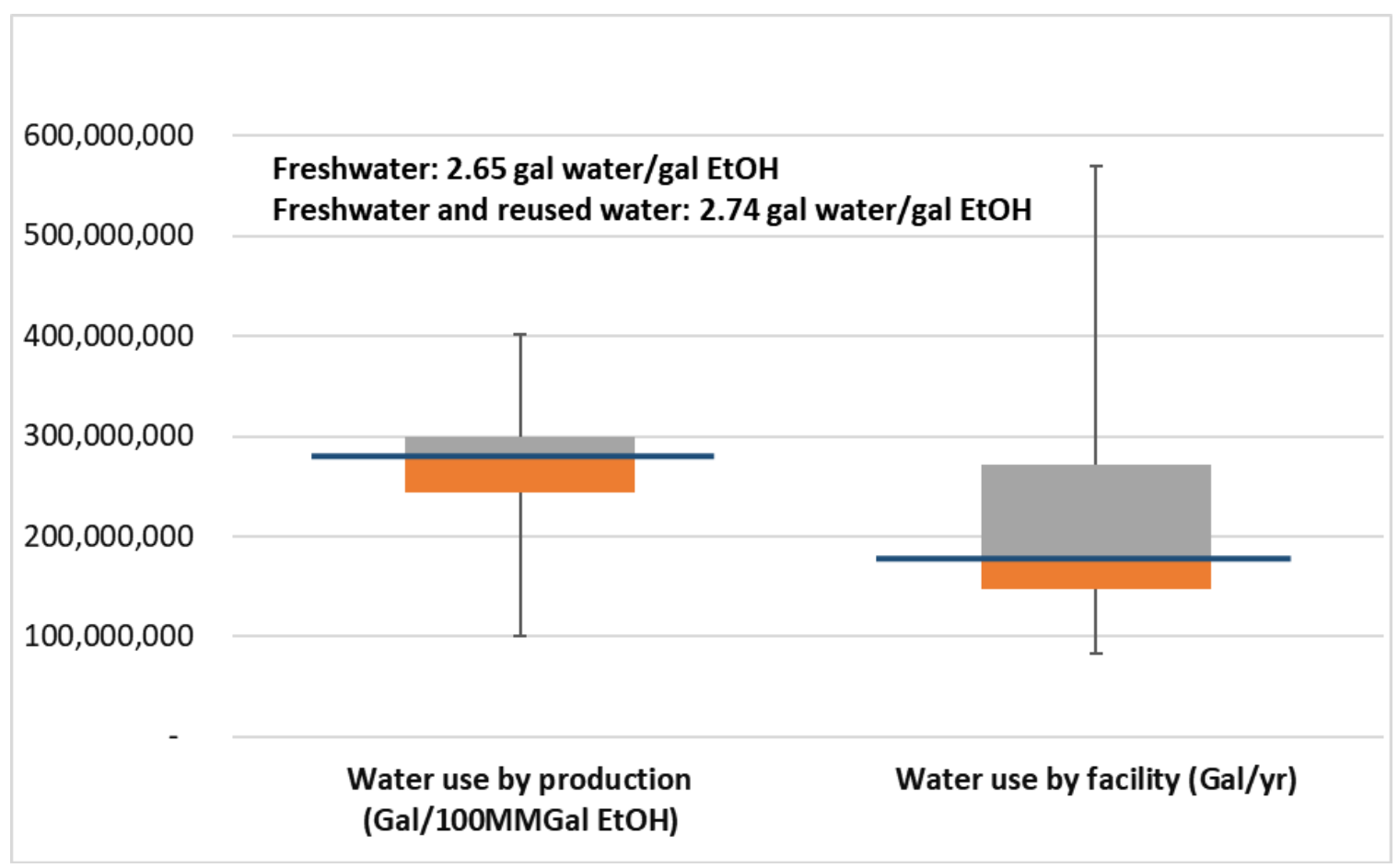

FIGURE 17 Water intensity (fresh and reused water): maximum, 75th percentile, median, 25th percentile, and minimum value of water consumption per 100 million gallons of ethanol produced, and total gallons of water consumption per production facility. The centerline inside the boxes represents the median value. The top of the gray box displays the 75th percentile, and the bottom of the orange box displays the 25 th percentile. The maximum and minimum values are displayed with vertical lines ("whiskers") connecting the points to the center boxes. 


\section{Water Conservation through Increased Use, Recycle and Reuse}

Water pumped to cooling units and boilers is subject to pre-treatment. Reverse osmosis (RO) is a typical pretreatment technology for cooling water. The survey found that a number of plants implemented two-step pre-treatments using ultra-filtration (UF) or greensand iron removal preceding RO. These additional treatments were reported by about 19 and $38 \%$ of the facilities, respectively (Figure 18). For boiler water pretreatment, both RO and softeners were applied in all responding facilities. Statistical analyses of cycles of concentration for cooling towers and boilers are presented in Figures 19 and 20, respectively. Cooling towers ran 8.3 cycles of concentration, on average, with a 25th percentile of 5 cycles, median of 7 cycles, and 75th percentile of 10 cycles. The lowest number of cycles reported was 2 , and the highest was 24 . As expected, cycles of concentration for boilers averaged 45, spanning the range from 22 to 52 cycles at the 25th, median, and 75th percentile, and with a maximum value of 137 and a minimum of 7. Increased cycles in cooling units and boilers represent increased use (i.e., a longer use period) of water resources, therefore conserving fresh water. Longer operation means less bleeding/blowdown, which would lead to a lower makeup water requirement. On the other hand, increased cycles also mean concentrating components in the water because of more evaporative water loss during the operation, which may increase the energy demand. Operations that reduce water input by increasing the number of cycles while maintaining energy use at the same level would be highly preferred.

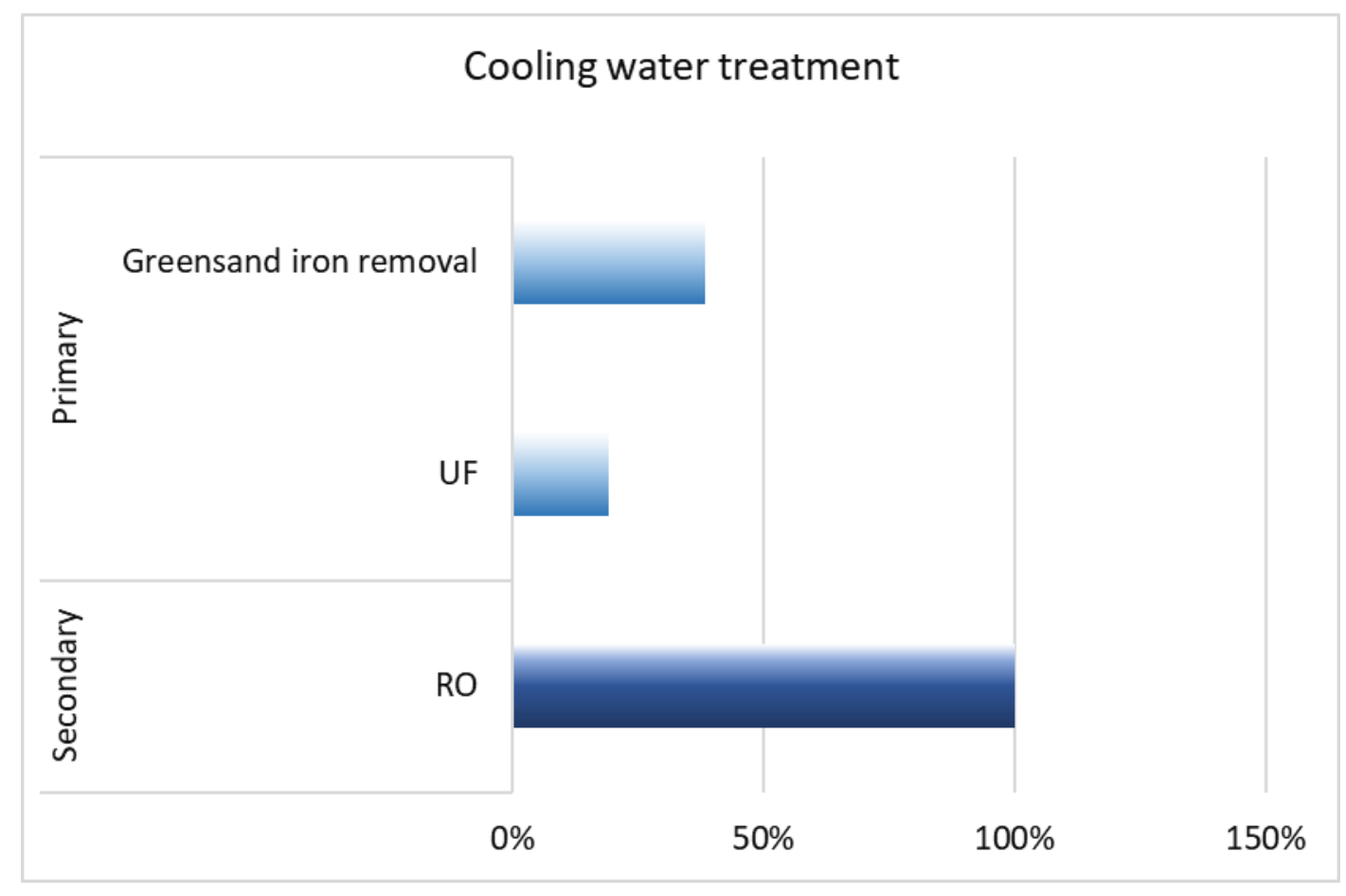

FIGURE 18 Cooling water treatment technologies. 


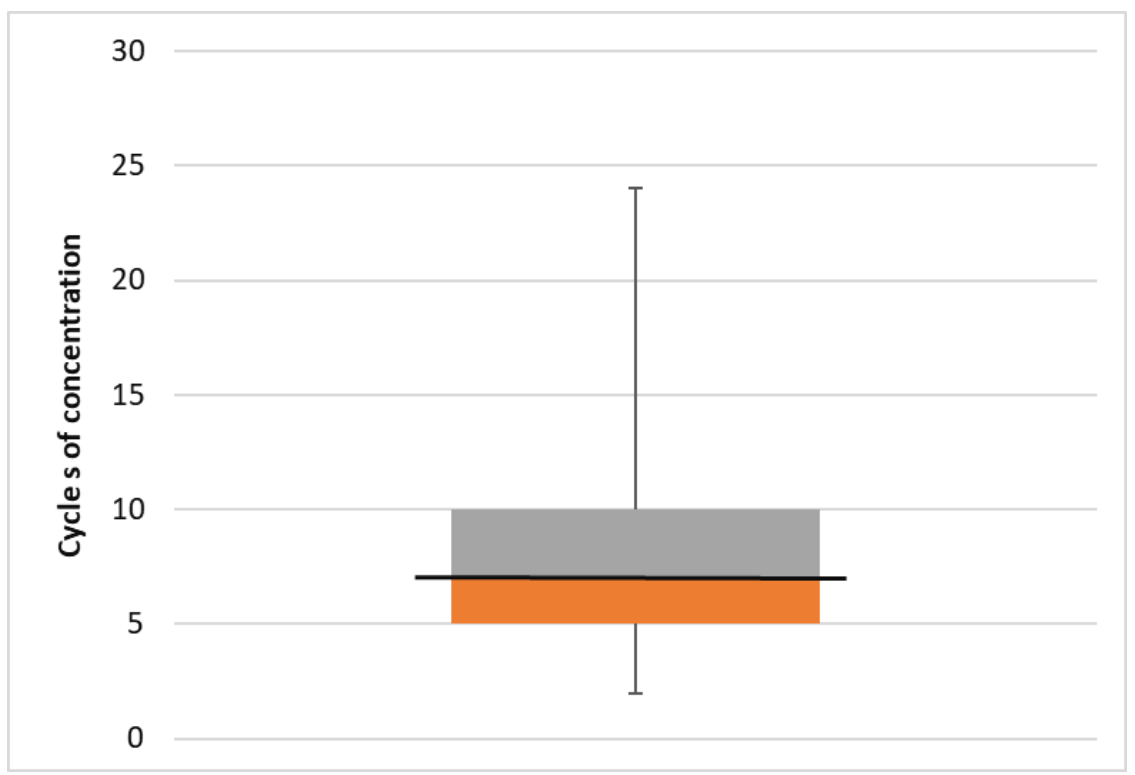

FIGURE 19 Cooling-tower cycles of concentration: maximum, 75th percentile, median, 25th percentile, and minimum value of cycles of concentration. The centerline inside the boxes represents the median value. The top of the gray box displays the 75 th percentile, and the bottom of the orange box displays the 25 th percentile. The maximum and minimum values are displayed with vertical lines ("whiskers") connecting the points to the center boxes.

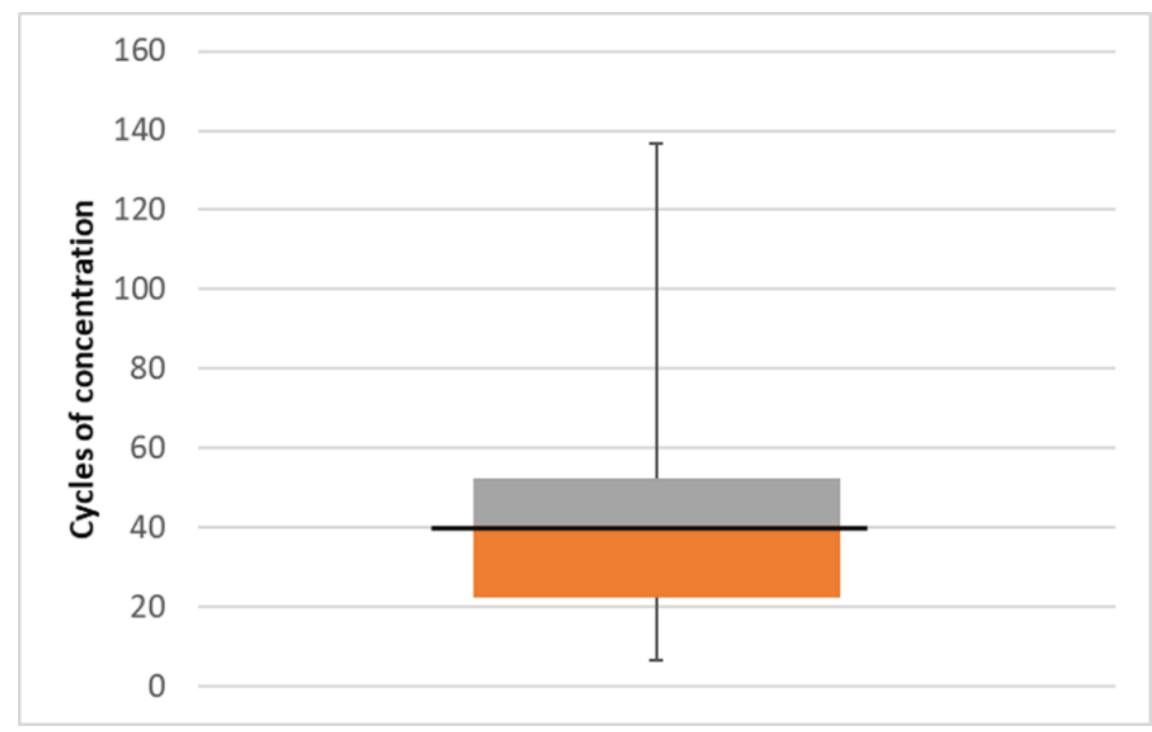

FIGURE 20 Boiler cycles of concentration: maximum, 75th percentile, median, 25th percentile, and minimum values. The centerline inside the boxes represents the median value. The top of the gray box displays the 75th percentile, and the bottom of the orange box displays the 25th percentile. The maximum and minimum values are displayed with vertical lines ("whiskers") connecting the points to the center boxes. 
As we discussed in the section "Water Resources and Water Intensity," reduction of water intensity in biofuel plants results from multiple factors. In addition to increasing cycles in cooling units and boilers, facilities made efforts to reduce water intensity by recycling water to fermentation processes. Dry mill generates little process wastewater from fermentation and downstream processing. A majority of wastewater were blowdown water from cooling system and boiler. The survey data revealed that among the facilities responded to wastewater questions $(94 \%)$, more than a third of facilities $(36.1 \%)$ recycled blowdown water from the cooling tower and boiler to the fermentation unit, which also supplies liquid and minerals needed for enzymatic conversion processes (Figure 21). Eighteen percent of the facilities sent the wastewater offsite to a local publicly owned treatment works (POTW), and less than a half (45.9\%) treat it on-site through various means such as evaporation pond, settling pond, and other chemical treatment to meet regulated discharge limits. For the facilities that recycle water back to fermenters, there is no more wastewater discharge, and a goal of many manufacturing operations-zero liquid discharge (ZLD) - is achieved without compromising the product quality. This is clearly a sign of progress in water conservation in the biofuel industry. We expect that this trend will continue.

Another way to reduce water intensity in current biofuel production is to conserve water in coproducts so that it can be reused for other purposes. As we elucidated in the "Product Portfolio and Yields" section, drying DDGS (to $12 \%$ moisture, Figure 14) represents a significant water loss through evaporation. Wet DGS or MWDG that contains high moisture can supply both nutrients and water to meet the dietary needs of beef cattle and other animals (Figure 14). When WDG and MWDG are sold as animal feed to a feedlot, the water contained in the feed is reused. This multi-stage water use from an ethanol dry mill to a feedlot provides water conservation that benefits both the biofuel and animal feed industries. Finally, water resources can be conserved in a plant through better steam system integration. New plant design in the last two decades has improved water efficiency significantly. This improvement has been evident both historically (Wu et al. 2009, Mueller and Kwik 2013) and from the present survey (Figure 17). These newer plants often incorporate more efficient process design. When older plants are retired and the dominance of new plants increases (Figure 1), the industry benchmark of water intensity will decrease further. 


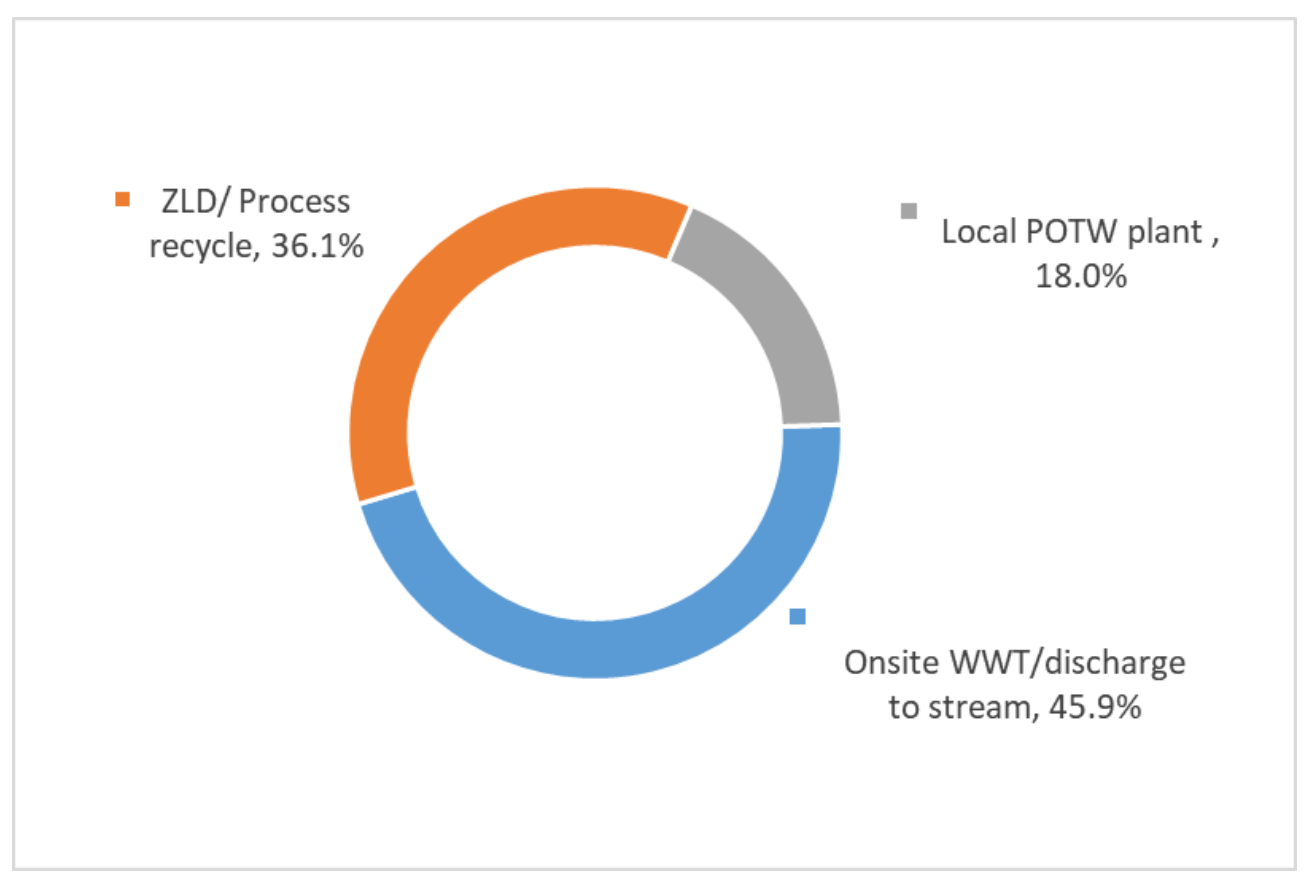

FIGURE 21 Fate of wastewater from biofuel production facilities.

\section{Cost of Water and Energy}

An important factor that influences the sustainability of both production and environmental impacts is the cost of water and energy. Freshwater cost is heterogeneous across the U.S. because of diverse freshwater resource availability in various regions. The survey found that among the facilities reporting freshwater cost (71\%), it takes a weighted average of $\$ 2.05$ to procure a thousand gallons of fresh water. Figure 22 presents the maximum, 75 th percentile, median, 25th percentile, and minimum value of freshwater cost to ethanol production facilities. Most plants spent from $\$ 0.77$ to $\$ 3.34$ (25th percentile to 75 th percentile) for 1000 gallons. These expenditures include water from city waterworks and some wells. A few facilities were able to retrieve water from a plant-owned private well or lake, thus incurring no cost for the water resource. Costs of alternative water supplies vary significantly, ranging from near zero to double the freshwater average.

Wastewater treatment was charged in two different ways. Twenty seven percent of the facilities that elect to discharge the wastewater to sewer is charged by local POTW based on the volume of wastewater. Local water and wastewater management programs in some areas may package the prices for fresh water and wastewater treatment together for a facility. In that case, the wastewater treatment cost is included in the freshwater cost. This arrangement applies to remainder $73 \%$ of the plants, and is reflected in the high-end value of freshwater cost in Figure 22. 


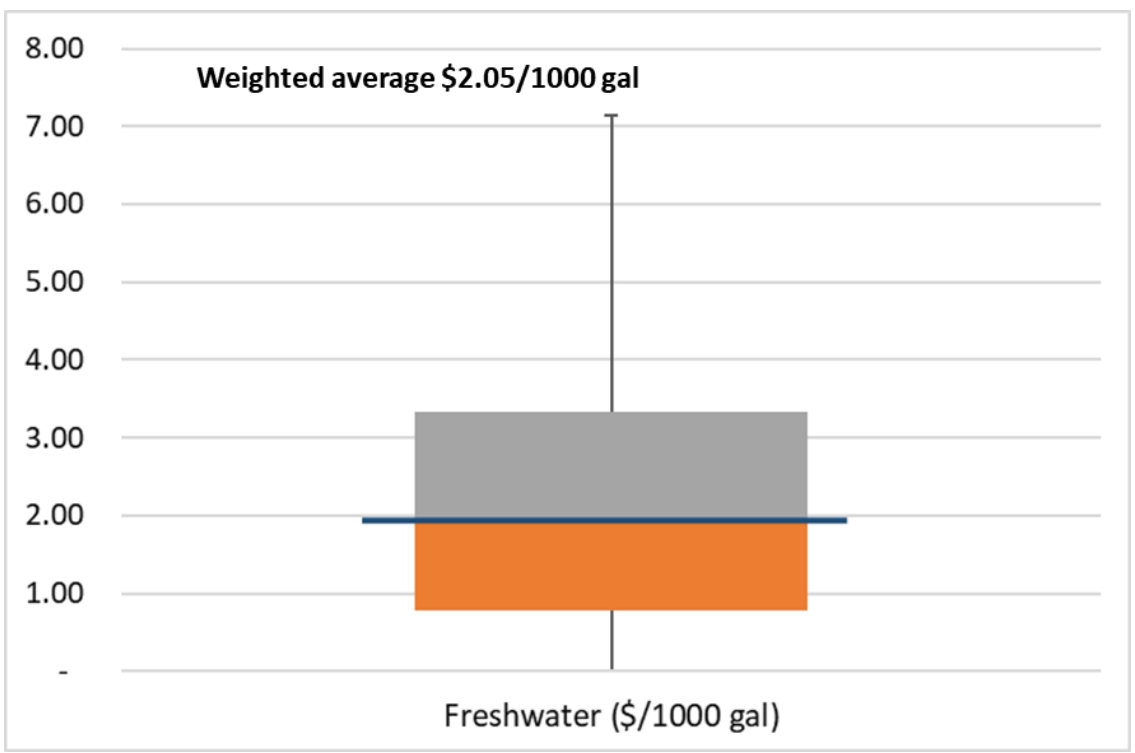

FIGURE 22 Maximum, 75th percentile, median, 25th percentile, and minimum freshwater cost to ethanol facilities in dollars per 1000 gallons of fresh water. The centerline inside the boxes represents the median cost. The top of the gray box displays the 75th percentile, and the bottom of the orange box displays the 25 th percentile. The maximum and minimum values are displayed with vertical lines ("whiskers") connecting the points to the center boxes.

The cost of wastewater discharge is relatively small for most plants. Most surveyed plants $(82 \%)$ discharged on-site treated wastewater at no cost to a stream; only the remaining $18 \%$ discharged to local POTWs) were burdened. Those plants that were directly charged for wastewater treatment experienced an average rate of \$5.81 per 1000 gallons of wastewater leaving the plant. Again, the POTW charge rate for industrial water varies widely, depending on treatment capacity and treatment demand.

In contrast to water and wastewater, the cost of natural gas supply is less variable, with a production-weighted average of \$3.95 per million Btu in 2017 (Figure 23). Statistics indicated a very narrow band of $\$ 3.31$ to $\$ 3.66$ per million $B$ tu, from the 25 th percentile to the $75^{\text {th }}$ percentile, which suggests geographically homogeneous natural gas costs in 2017 . Two facilities reported more than $\$ 12$ per million Btu, far above the remaining facilities. Without those two, the average value for natural gas would drop to $\$ 3.47$ per million Btu. 


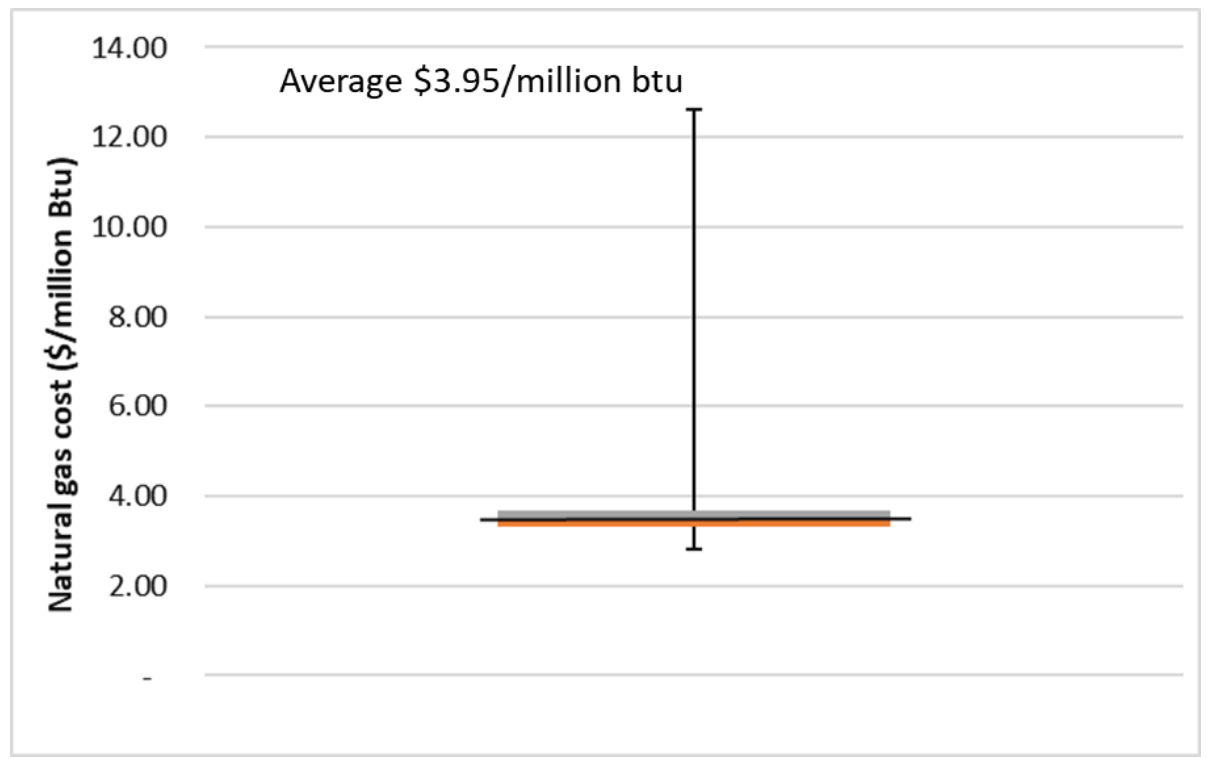

FIGURE 23 Natural gas cost: maximum, 75th percentile, median, 25th percentile, and minimum values. The centerline inside the boxes represents the median value. The top of the gray box displays the 75 th percentile, and the bottom of the orange box displays the 25th percentile. The maximum and minimum values are displayed with vertical lines ("whiskers") connecting the points to the center boxes. 


\section{CONCLUSIONS}

The biofuel industry has made a conscious effort to conserve resources, diversify product portfolio, recycle and reuse water, while improve productivity. According to survey responses, freshwater intensity has decreased by $12 \%$ since 2011 and by $54 \%$ over the 19 years from 1998 to 2017. Five percent of plants have implemented on-site electricity generation to replace grid electricity, and several plants have become net electricity exporters. Newer plants that were built after 2000 dominate biofuel plants in the U.S. Co-processing of corn kernel fiber with grain to produce ethanol has become attractive, with its potential $2.5 \%$ increase in yield relative to grain processing alone. In 2017, 2.81 gallons of ethanol were produced from the starch in a bushel of grain, while 2.88 gallons of ethanol were produced from the starch and fiber in a bushel of grain. Growing numbers of facilities began co-processing corn fiber ethanol. $\mathrm{CO}_{2}$ extraction and export are on the rise for increased revenue, whereas electricity expenditure for $\mathrm{CO}_{2}$ compressing is also increasing. In the area of water resource, the survey found that biofuel plants diversified their water sources by using such alternatives as power-plant cooling water and municipal reclaimed water, in addition to well water and city water. Water and wastewater management is progressing toward ZLD. The survey found more than a third (36.1\%) in-plant water reuse and recycle through cycle cooling and through diverting boiler blowdown water to fermentation processes. Plants also conserve water by omitting the coproduct drying step, which reduces energy demand, and increasing production of WDG and MWDG. The water content in these coproducts is reused in feedlots as a part of the animals' diet. Analysis of survey results demonstrated that the industry emphasizes the FEW nexus while increasing production in a way that is energyefficient, water-efficient, and environmentally sustainable. 


\section{REFERENCES}

1. Biofuel International Magazine, 2019. California approves Edeniq customers for corn ethanol production, https://biofuels-news.com/display_news/14675/california_approves_ edeniq_customers_for_corn_ethanol_production/

2. BR\&D (Biomass Research and Development Board), 2019. The Bioeconomy Initiative: Implementation Framework, https://biomassboard.gov/pdfs/Bioeconomy_Initiative Implementation_Framework_FINAL.pdf

3. EIA (U.S. Energy Information Administration), 2018. Today in Energy: U.S. fuel ethanol production capacity continues to increase, https://www.eia.gov/todayinenergy/detail. php?id=36774

4. Fang, Y., and J. W. Jawitz, 2019. The evolution of human population distance to water in the USA from 1790 to 2010, Nature Communications, Volume 10 (1), Article number 430. https://www.nature.com/articles/s41467-019-08366-z, DOI: $\underline{10.1038 / \mathrm{s} 41467-019-08366-\mathrm{Z}}$

5. Grubert, E., and K. T. Sanders, 2018. Water use in the United States energy system: A national assessment and unit process inventory of water consumption and withdrawals, Environmental Science \& Technology, Volume 52, pp. 6695-6703, https://doi.org/10.1021/acs.est.8b00139

6. Keeney, D., and M. Muller, 2006. Water Use by Ethanol Plants: Potential Challenges. The Institute for Agriculture and Trade Policy, Minneapolis, MN, Oct.

7. Liu, J., G. Mao, A. Y. Hoekstra, H. Wang, J. Wang, C. Zheng, M. T. H. van Vliet, M. Wu, B. Ruddel, and J. Yan, 2018. Managing the energy-water-food nexus for sustainable development, Applied Energy, Special Issue on Energy-Water-Food Nexus, Volume 210, pp. 377-381, https://doi.org/10.1016/j.apenergy.2017.10.064

8. López-Díaz, D. C., L. F. Lira-Barragán, E. Rubio-Castro, M. Serna-González, M. M. ElHalwagi, and J. M. Ponce-Ortega, 2018. Optimization of biofuels production via a waterenergy-food nexus framework, Clean Technologies and Environmental Policy, Volume 20, Issue 7, pp $\overline{\bar{\prime} .}$ 1443-1466, https://doi.org/10.1007/s10098-017-1395-0

9. Martín, M., and I. E. Grossmann, 2015. Water-energy nexus in biofuels production and renewable based power, Sustainable Production and Consumption, Volume 2, pp. 96-108, https://doi.org/10.1016/j.spc.2015.06.005

10. Mueller. S., and J. Kwik, 2013. 2012 Corn Ethanol: Emerging Plant Energy and Environmental Technologies, UIC Energy Resources Center, April. 
11. Oliveira, M. C., M. Iten, H. A. Matos, and J. Michels, 2019. Water-energy nexus in typical industrial water circuits, Water, Volume 11, Issue 4, p. 699, https://doi.org/10.3390/w11040699

12. Phillips, S., A. Aden, J. Jechura, D. Dayton, and T. Eggeman, 2007. Thermochemical Ethanol via Indirect Gasification and Mixed Alcohol Synthesis of Lignocellulosic Biomass, Technical Report NREL/TP-510-41168, National Renewable Energy Laboratory, April.

13. POET, 2011. Press Releases: POET Cuts Water Use by More Than 400 Million Gallons. https://poet.com/pr/poet-cuts-water-use-by-more-than-400-million-gallons. Accessed May $23,2019$.

14. Renewable Fuels Association, n.d. Annual Fuel Ethanol Production, https://ethanolrfa.org/statistics/annual-ethanol-production/. Accessed May 7, 2019.

15. Renewable Fuels Association, n.d. Ethanol Biorefinery Locations, https://ethanolrfa.org/biorefinery-locations/ . Accessed July 31, 2019.

16. Shapouri, H., and P. Gallagher, 2005. 2002 Ethanol Cost-of-Production Survey, U.S. Department of Agriculture, July.

17. Silalertruksa, T., and S. H. Gheewala, 2019. Land-water-energy nexus of biofuels development in emerging economies: A case study of bioethanol policy in Thailand. In: C. Lago, N. Caldés and Y. Lechón, eds., The Role of Bioenergy in the Emerging Bioeconomy: Resources, Technologies, Sustainability and Policy, Academic Press, pp. 379-402, https://doi.org/10.1016/B978-0-12-813056-8.00008-X

18. State CO2-EOR Deployment Work Group, 2017. Capturing and Utilizing $\mathrm{CO}_{2}$ from Ethanol: Adding Economic Value and Jobs to Rural Economies and Communities While Reducing Emissions, White Paper, December.

19. Thiede, S., D. Kurle, and C. Herrmann, 2017. The water-energy nexus in manufacturing systems: Framework and systematic improvement approach, CIRP Annals, Volume 66, Issue 1, pp. 49-52, https://doi.org/10.1016/j.cirp.2017.04.108

20. Urbanchuk, J., 2010. Current State of the U.S. Ethanol Industry, report prepared for the U.S. Department of Energy, Nov., https://www.energy.gov/sites/prod/files/2014/04/f14/current_state_of the_us_ethanol_indus try.pdf

21. Warner, E., A. Schwab A., and D. Bacovsky, 2017. 2016 Survey of Non-Starch Alcohol and Renewable Hydrocarbon Biofuels Producers, Technical Report NREL/TP-6A10-67539, National Renewable Energy Laboratory, Feb. 
22. Wu, M., 2008. Analysis of the Efficiency of the U.S. Ethanol Industry 2007. https://www.energy.gov/sites/prod/files/2014/04/f14/anl_ethanol_analysis_2007.pdf. Accessed May 23, 2019.

23. Wu, M., M. Mintz, M. Wang, S. Arora, Y-W Chiu, and H. Xu, 2018. Consumptive Water Use in the Production of Ethanol and Petroleum Gasoline-2018 Update. Technical Report ANL/ESD-09/01 Rev.2, DOE-OSTI, ID 1490723, Argonne National Laboratory, http://water.es.anl.gov/documents/ANL_ESD_09-1_Update\%202018.pdf

24. Wu, M., M. Mintz, M. Wang, and S. Arora, 2009. Water consumption in the production of ethanol and petroleum gasoline, Environmental Management, Volume 44, pp. 981-997, DOI 10.1007/s00267-009-9370-0.

25. Xu, H., M. Wu, and M. Ha, 2019. A county-level estimation of renewable surface water and groundwater availability associated with potential large-scale bioenergy feedstock production scenarios in the United States, GCB Bioenergy, Volume 11, pp. 606-622, https://doi.org/10.1111/gcbb.12576 


\section{APPENDICES}

1 SURVEY FORMS FOR ETHANOL PLANTS 


\section{Argonne}

\section{Ethanol Plant Energy and Water Use Survey}

All surveys marked as Proprietary will remain the property of the discloser, be maintained by Argonne in confidence for five years, and will only be used for the purpose of conducting this study. At the conclusion of five years, the documents will be returned, erased or destroyed. Submitters agree that only the statistically aggregated results from the data

received will be published by Argonne in the public domain.

Please fill out all that apply with Calendar Year 2017 data for each individual ethanol plant.

1) Company Name:

2) Plant Location: State County

3) Plant Startup Year:

4) Maximum Operating Capacity: Gallons (on an anhydrous/un-denatured basis)

5) 2017 Total Production: Gallons (on an anhydrous/un-denatured basis)

6) Feed Stock Source: State(s)

7) Feedstock Type by Percent Share of Total Ethanol Processed (un-denatured basis):

Corn Grain:

$\%$

Corn Kernel Fiber: $\%$

Grain Sorghum: $\%$ Other Grains: $\%$

Food/beverage Processing Waste: $\%$

Corn Stover: $\%$

Other Cellulosic: $\%$

8) If you process cellulosic feedstock (e.g., corn kernel fiber or corn stover) into cellulosic ethanol, which conversion process do you use? (Circle one)

- Separate/Stand-alone Cellulosic Fermentation

- Simultaneous (in situ) Co-processing of Starch and Cellulosic

13). Cost of freshwater supply (\$ per 1000 gallons):

14). Cost of fuel (NG) (\$/million BTU):

15). Plant process wastewater discharge to

- Local POTW plant

- River outfall

- Others: Specify

- Cost of wastewater leaving the plant (\$ per 1000 gallons):

16). Do you plan for on-site wastewater treatment in the next five years?

- Yes No 


\section{Argonne}

Please state ethanol values on an anhydrous/un-denatured basis (below).

\begin{tabular}{|c|c|c|c|c|}
\hline Inputs/Outputs & Quantity & Units & Instruction & Comments \\
\hline $\begin{array}{l}\text { Ethanol Yield, } \\
\text { Grain }\end{array}$ & & Gallons/bushel & & \\
\hline \multirow{2}{*}{$\begin{array}{l}\text { Ethanol Yield, } \\
\text { Grain and corn fiber }\end{array}$} & & Gallons/bushel & Grain ethanol & \\
\hline & & Gallons/bushel & Stand-alone process & \\
\hline $\begin{array}{l}\text { Ethanol Yield, } \\
\text { Grain and corn fiber }\end{array}$ & & Gallons/bushel & Co-processing & \\
\hline $\begin{array}{l}\text { Ethanol Yield, } \\
\text { Cellulosic }\end{array}$ & & Gallons/dry ton & $\begin{array}{l}\text { Corn Stover, other residue and } \\
\text { cellulosic }\end{array}$ & \\
\hline $\begin{array}{l}\text { Electricity Use } \\
\text { (total plant use) }\end{array}$ & & Kwh/Gallon & $\begin{array}{l}\text { Grid__ } \% \\
\text { Internal biomass___ } \%\end{array}$ & \\
\hline \multirow{2}{*}{$\begin{array}{l}\text { Co-generation } \\
\text { (using biomass) }\end{array}$} & Electricity: & Kwh/gallon & & \\
\hline & Steam: & Btu or lbs /Gallon & Specify: Steam temperature & \\
\hline $\begin{array}{l}\text { Thermal Energy Use } \\
\text { (total plant use) }\end{array}$ & & Btu/Gallon & $\begin{array}{l}\text { Exclude electricity \&co-gen, } \\
\text { lower heating value basis }\end{array}$ & \\
\hline \multirow{4}{*}{$\begin{array}{l}\text { Plant Thermal Energy } \\
\text { Fuel Source } \\
\text { (break down) }\end{array}$} & NG: & \multirow{4}{*}{$\begin{array}{l}\% \text { of total thermal } \\
\text { energy use } \\
\text { (based on Btu) }\end{array}$} & Natural gas & \multirow{4}{*}{$\begin{array}{l}\text { Exclude } \\
\text { Electricity } \\
\text { and co-gen }\end{array}$} \\
\hline & Coal: & & & \\
\hline & Biomass: & & & \\
\hline & Others: & & Specify: & \\
\hline DDGS Produced & & Lbs./Gallon & & $\begin{array}{l}\text { with moisture } \\
\text { as sold }\end{array}$ \\
\hline $\begin{array}{l}\text { DDGS moisture } \\
\text { content }\end{array}$ & & $\%$ & & \\
\hline WDG Produced & & Lbs./Gallon & & $\begin{array}{l}\text { with moisture } \\
\text { as sold }\end{array}$ \\
\hline $\begin{array}{l}\text { WDG moisture } \\
\text { content }\end{array}$ & & $\%$ & & \\
\hline Corn Oil Separated & & $\begin{array}{l}\text { Gallons of oil } \\
\text { / gallon }\end{array}$ & $\begin{array}{l}\text { Under maximum } \\
\text { operating conditions }\end{array}$ & \\
\hline $\begin{array}{l}\text { Other } \\
\text { Coproducts }\end{array}$ & & Lbs./gallon & Name of the coproducts: & \\
\hline $\begin{array}{l}\text { Total Plant } \\
\text { Freshwater Usage }\end{array}$ & & $\begin{array}{l}\text { Gallons/MM gal } \\
\text { EtOH }\end{array}$ & $\begin{array}{l}\text { Total freshwater input including } \\
\text { process, cooling, steam }\end{array}$ & \\
\hline
\end{tabular}

For questions call: 630-252-6658 or contact mwu@anl.gov. Return the filled form to mwu@anl.gov 


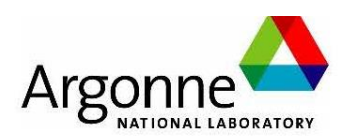

\section{Ethanol Plant Energy and Water Use Survey}

We are conducting an update to the "2012 Corn Ethanol Survey" which helped highlight the dynamic improvements to the corn ethanol environmental footprint. Since then, additional improvements in energy-efficiency and process-water management have been adopted by plants, which need to be documented to demonstrate the continuous improvement in the environmental footprint of the ethanol industry.

All surveys marked as Proprietary will remain the property of the discloser, be maintained by Argonne in confidence for five years, and will only be used for the purpose of conducting this study. At the conclusion of five years, the documents will be returned, erased or destroyed. Submitters agree that only the statistically aggregated results from the data received will be published by Argonne in the public domain.

Please fill out all that apply with Calendar Year 2017 data for each individual ethanol plant.

1) Company Name:

2) Plant Location: State County

3) Plant Startup Year:

4) Maximum Operating Capacity: Gallons (on an anhydrous/ $\underline{\text { un-denatured basis) }}$

5) 2017 Total Production: Gallons (on an anhydrous/un-denatured basis)

6) Feed Stock Source: State(s)

7) Feedstock Type by Percent Share of Total Ethanol Processed (un-denatured basis):

$\begin{array}{llll}\text { Corn Grain: } & \text { Corn Kernel Fiber: } & \\ \text { Grain Sorghum: } & \% & \text { Other Grains: }\end{array}$




\section{Argonne}

8) If you process cellulosic feedstock (e.g., corn kernel fiber or corn stover) into cellulosic ethanol, which conversion process do you use? (Circle one)

- Separate/Stand-alone Cellulosic Fermentation

- Simultaneous (in situ) Co-processing of Starch and Cellulosic

9). Cooling System

- Cooling System Type (circle one):

- Recirculating tower

- Cooling pond

○ Once-through

- Number of Cooling Concentration Cycles

- Types of Pretreatment for Water (check all that apply)

- Reverse osmosis

Clarifier

- Softeners Sand filters

$\circ$ Others: (specify)

- Electricity Usage (kwh/gallons)

10). Boiler

- Fuel Source: NG fired Coal fired Biomass/coal fired

- Number of Concentration Cycles:

- Steam Temperature ( $\left.{ }^{\circ} \mathrm{F}\right)$ Pressure (psig):

- Types of Pretreatment for Water (check all that apply):

○ RO:

○ Softeners:

O Others: (specify) 


\section{Argonne}

- Has the plant switched boiler water pretreatment from softener to RO in last five years?

- Yes (Move to next question)

- No (Skip next question and move to 11)

- Changes of energy and water consumption due to the switching (annual basis)

- Before:

- Blowdown rate: $\%$

- Steam flow (lb/hr):

- Feedwater mass flow (gallon/hr):

- Fuel energy use (BTU/lb steam):

- After

- Blowdown rate__ $\%$

- Steam flow (lb/hr)

- Feed water mass flow (gallon/hr):

- Fuel energy use (BTU/lb steam):

11). Plant Water Source (select and circle all that apply)

- Public water system

- Private well

- Surface water intake

- Others: Specify

12). Alternative water resource

- Is the plant currently using alternative water resource? Yes No

- Reclaimed water 


\section{Argonne}

- Saline water
- Cost of alternative water resource supply (\$ per 1000 gallons):

- Do you plan to use reclaimed water as a part of your source water in next five years? Yes__ No

13). Cost of freshwater supply ( $\$$ per 1000 gallons):

14). Cost of fuel (NG) (\$\$/million BTU):

15). Plant process wastewater discharge to

- Local POTW plant

- River outfall

- Others: Specify

- Cost of wastewater leaving the plant (\$ per 1000 gallons):

16). Do you plan for on-site wastewater treatment in the next five years?

- Yes No

17). Water Reuse/Recycle in the plant: (circle one)

- Yes No

18) If Yes to 17) where the water is reused for and/or recycled to?

- Recycled to inlet to water treatment to others (specify)

- Directly reused for process , for others (specify)

19). Cooling and boiler blowdown discharge to

- Local POTW

- Permitted discharge to 


\section{Argonne 4}

Please state ethanol values on an anhydrous/un-denatured basis (below).

\begin{tabular}{|c|c|c|c|c|}
\hline Inputs/Outputs & Quantity & Units & Instruction & Comments \\
\hline $\begin{array}{l}\text { Ethanol Yield, } \\
\text { Grain }\end{array}$ & & Gallons/bushel & & \\
\hline \multirow{2}{*}{$\begin{array}{l}\text { Ethanol Yield, } \\
\text { Grain and corn fiber }\end{array}$} & & Gallons/bushel & Grain ethanol & \\
\hline & & Gallons/bushel & Stand-alone process & \\
\hline $\begin{array}{l}\text { Ethanol Yield, } \\
\text { Grain and corn fiber }\end{array}$ & & Gallons/bushel & Co-processing & \\
\hline $\begin{array}{l}\text { Ethanol Yield, } \\
\text { Cellulosic }\end{array}$ & & Gallons/dry ton & $\begin{array}{l}\text { Corn Stover, other residue and } \\
\text { cellulosic }\end{array}$ & \\
\hline $\begin{array}{l}\text { Electricity Use } \\
\text { (total plant use) }\end{array}$ & & Kwh/Gallon & $\begin{array}{l}\text { Grid___ } \% \\
\text { Internal biomass___ } \%\end{array}$ & \\
\hline \multirow{2}{*}{$\begin{array}{l}\text { Co-generation } \\
\text { (using biomass) }\end{array}$} & Electricity: & Kwh/gallon & & \\
\hline & Steam: & Btu or lbs /Gallon & Specify: Steam temperature & \\
\hline $\begin{array}{l}\text { Thermal Energy Use } \\
\text { (total plant use) }\end{array}$ & & Btu/Gallon & $\begin{array}{l}\text { Exclude electricity \& co-gen, } \\
\text { lower heating value basis }\end{array}$ & \\
\hline \multirow{4}{*}{$\begin{array}{l}\text { Plant Thermal Energy } \\
\text { Fuel Source } \\
\text { (break down) }\end{array}$} & NG: & \multirow{4}{*}{$\begin{array}{l}\% \text { of total thermal } \\
\text { energy use } \\
\text { (based on Btu) }\end{array}$} & Natural gas & \multirow{4}{*}{$\begin{array}{l}\text { Exclude } \\
\text { Electricity } \\
\text { and co-gen }\end{array}$} \\
\hline & Coal: & & & \\
\hline & Biomass: & & & \\
\hline & Others: & & Specify: & \\
\hline DDGS Produced & & Lbs./Gallon & & $\begin{array}{l}\text { with moisture } \\
\text { as sold }\end{array}$ \\
\hline $\begin{array}{l}\text { DDGS moisture } \\
\text { content }\end{array}$ & & $\%$ & & \\
\hline WDG Produced & & Lbs./Gallon & & $\begin{array}{l}\text { with moisture } \\
\text { as sold }\end{array}$ \\
\hline
\end{tabular}


Argonne

\begin{tabular}{|c|c|c|c|c|}
\hline Inputs/Outputs & Quantity & Units & Instruction & Comments \\
\hline $\begin{array}{l}\text { WDG moisture } \\
\text { content }\end{array}$ & & $\%$ & & \\
\hline Corn Oil Separated & & $\begin{array}{l}\text { Gallons of oil } \\
\text { / gallon }\end{array}$ & $\begin{array}{l}\text { Under maximum } \\
\text { operating conditions }\end{array}$ & \\
\hline $\begin{array}{l}\text { Other } \\
\text { Coproducts }\end{array}$ & & Lbs./gallon & Name of the coproducts: & \\
\hline $\begin{array}{l}\text { Total Plant } \\
\text { Freshwater Usage }\end{array}$ & & $\begin{array}{l}\text { Gallons/MM gal } \\
\text { EtOH }\end{array}$ & $\begin{array}{l}\text { Total freshwater input including } \\
\text { process, cooling, steam }\end{array}$ & \\
\hline Cooling Water Usage & & $\begin{array}{l}\text { Gallons/MM gal } \\
\text { EtOH }\end{array}$ & Freshwater & \\
\hline Steam Water Usage & & $\begin{array}{l}\text { Gallons/MM gal } \\
\text { EtOH }\end{array}$ & Freshwater & \\
\hline $\begin{array}{l}\text { Process Water } \\
\text { Usage }\end{array}$ & & $\begin{array}{l}\text { Gallons/MM gal } \\
\text { EtOH }\end{array}$ & Freshwater & \\
\hline $\begin{array}{l}\text { Total Plant } \\
\text { Alternative Water } \\
\text { Usage }\end{array}$ & & $\begin{array}{l}\text { Gallons/MM gal } \\
\text { EtOH }\end{array}$ & $\begin{array}{l}\text { Saline__ } \% \\
\text { Reclaimed _ } \\
\text { Others, specify _ }\end{array}$ & $\begin{array}{l}\text { Excluding } \\
\text { internal reuse } \\
\text { and recycle }\end{array}$ \\
\hline $\begin{array}{l}\text { Total Wastewater } \\
\text { Discharge }\end{array}$ & & $\begin{array}{l}\text { Gallons/MM gal } \\
\text { EtOH }\end{array}$ & $\begin{array}{l}\text { Local POTW__ } \% \\
\text { River outfall__ } \% \\
\text { Ship to non-local POTW___ } \% \\
\text { Others: Specify }\end{array}$ & \\
\hline $\begin{array}{l}\text { Wastewater } \\
\text { Recycle }\end{array}$ & & $\begin{array}{l}\text { Gallons/MM gal } \\
\text { EtOH }\end{array}$ & $\begin{array}{l}\text { Process: } \\
\text { Cooling: } \\
\text { Boiler: } \\
\text { Agriculture use: } \\
\text { Others: Specify }\end{array}$ & \\
\hline $\begin{array}{l}\text { Waste Solids } \\
\text { Moisture Content }\end{array}$ & & (\%) wt/wt & $\begin{array}{l}\text { Circle one: } \\
\text { dried, not dried }\end{array}$ & \\
\hline $\begin{array}{l}\text { Waste Solids } \\
\text { Disposal/Use }\end{array}$ & & $\begin{array}{l}\text { Ibs/MM gal } \\
\text { EtOH }\end{array}$ & $\begin{array}{l}\text { Please specify: }(w t / w t) \\
\text { Land fill_ } \% \\
\text { Soil amendment } \% \\
\text { Others }\end{array}$ & $\begin{array}{l}\text { Filter media, } \\
\text { wastewater } \\
\text { sludge, others }\end{array}$ \\
\hline
\end{tabular}




\section{Argonne}

For questions call: 630-252-6658 or contact mwu@anl.gov. Return the filled form to mwu@anl.gov 
2 SURVEY FORM FOR BIODIESEL PLANTS 


\section{Biodiesel Plant Energy and Water Use Survey}

All surveys marked as Proprietary will remain the property of the discloser, be maintained by Argonne in confidence for five years, and will only be used for the purpose of conducting this study. At the conclusion of five years, the documents will be returned, erased or destroyed. Submitters agree that only the statistically aggregated results from the data received will be published by Argonne in the public domain.

Please fill out all that apply with Calendar Year 2017 data for each individual plant. For questions call: 630-252-6658 or contact mwu@anl.gov.Return the filled form to mwu@anl.gov

1) Company Name:

2) Plant Location: State , County

3) Plant Startup Year:

4) Maximum Operating Capacity: Gallons of biodiesel

5) 2017 Total Production: Gallons of biodiesel

6) Feed Stock Source: State(s)

7) Feedstock Type by Percent Share of Total Biodiesel Processed:

Soybean oil:

Animal fats: $\%$ Recycled grease: Distillers' corn oil: $\%$

Canola oil: $\%$ Distillers' corn oil:

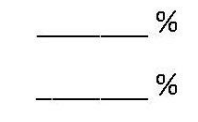

8) Cooling System

- Electricity use (kwh/gallons):

9) Boiler

- Fuel source: NG fired , Coal fired , Biomass/coal fired

- Fuel energy use (BTU/lb steam):

10) Plant Water Source (select and circle all that apply)

- Public water system, private well, surface water intake, others

12). Cost of freshwater supply (\$ per 1000 gallons):

13). Cost of fuel (NG, others, specify) (\$/million BTU):

14). Plant process wastewater and cooling/boiler blowdown discharge to (circle all that apply)

- Local POTW plant, Shipped to a non-local POTW, River outfall, Others: Specify

- Cost of wastewater leaving the plant (\$ per 1000 gallons):

16) Water Reuse/Recycle in the plant: (circle one)

- Recycled to inlet to water treatment other use (specify) , No 
Argonne

\begin{tabular}{|c|c|c|c|c|}
\hline Inputs/outputs & Quantity & Units & Instruction & Comments \\
\hline \multirow{2}{*}{ Biodiesel Yield } & & Gallons/lbs of oil & soybean oil, canola oil, corn oil & \\
\hline & & Gallons/lbs. & Lbs. of fat and grease & \\
\hline Soybean Oil Yield & & $\begin{array}{l}\text { Ibs of oil } \\
\text { /bushel of soybeans }\end{array}$ & $\begin{array}{l}\text { under maximum operating } \\
\text { conditions }\end{array}$ & $\begin{array}{l}\text { Crushing } \\
\text { facility }\end{array}$ \\
\hline $\begin{array}{l}\text { Electricity Use } \\
\text { (total plant use) }\end{array}$ & & Kwh/Gallon of BD & $\begin{array}{l}\text { Grid___ } \% \\
\text { Internal biomass___ } \%\end{array}$ & \\
\hline \multirow{2}{*}{$\begin{array}{l}\text { Co-generation } \\
\text { (biomass) }\end{array}$} & Electricity: & Kwh/Gallon of BD & & \\
\hline & Steam: & $\begin{array}{l}\text { Btu or lbs / Gallon } \\
\text { of } \mathrm{BD}\end{array}$ & Specify: Steam temperature & \\
\hline $\begin{array}{l}\text { Thermal Energy Use } \\
\text { (total plant use) }\end{array}$ & & Btu/Gallon of BD & $\frac{\text { Exclude electricity } \& \text { co-gen }}{\text { lower heating value basis }}$ & \\
\hline \multirow{4}{*}{$\begin{array}{l}\text { Plant Thermal Energy } \\
\text { Fuel Source } \\
\text { (break down) }\end{array}$} & NG: & \multirow{4}{*}{$\begin{array}{l}\% \text { of total thermal } \\
\text { energy use (based } \\
\text { on Btu) }\end{array}$} & Natural gas & \multirow{4}{*}{$\begin{array}{l}\text { Exclude } \\
\text { Electricity } \\
\text { and co-gen }\end{array}$} \\
\hline & Coal: & & & \\
\hline & Biomass: & & & \\
\hline & Others: & & Specify: & \\
\hline $\begin{array}{l}\text { Glycerin Produced } \\
\text { (with moisture) }\end{array}$ & & $\begin{array}{l}\text { Ibs/lbs of oil, } \\
\text { grease, and fat }\end{array}$ & & \\
\hline $\begin{array}{l}\text { Glycerin Moisture } \\
\text { Content }\end{array}$ & & $\%$ & & \\
\hline $\begin{array}{l}\text { Other } \\
\text { Coproducts }\end{array}$ & & $\begin{array}{l}\text { Ibs/gallon } \\
\text { of biodiesel }\end{array}$ & Name of the coproducts: & \\
\hline $\begin{array}{l}\text { Total Plant } \\
\text { Freshwater Usage }\end{array}$ & & Gallons/MM gal BD & $\begin{array}{l}\text { Total freshwater input } \\
\text { including process, cooling, } \\
\text { steam }\end{array}$ & \\
\hline Cooling Water Usage & & Gallons/MM gal BD & Freshwater & \\
\hline $\begin{array}{l}\text { Plant Wastewater } \\
\text { Discharge }\end{array}$ & & Gallons/MM gal BD & & \\
\hline $\begin{array}{l}\text { Waste Solids } \\
\text { Disposal }\end{array}$ & & Lbs/MM gal BD & $\begin{array}{l}\text { Land fill } \begin{array}{l}\%(w / w) \\
\text { Soil amendment } \\
\text { Others }\end{array} \%(w / w) \\
\%(w / w)\end{array}$ & $\begin{array}{l}\text { Spent catalyst, } \\
\text { filter media, } \\
\text { wastewater } \\
\text { sludge }\end{array}$ \\
\hline
\end{tabular}


Owing to limited responses from biodiesel plants, which accounted for less than $10 \%$ of the total production volume in 2017, we were not able to develop a meaningful and statistically representative analysis. Thus, this report does not include the results from the biodiesel plant survey. 

Energy Systems Division

Argonne National Laboratory

9700 South Cass Avenue, Bldg 362

Lemont IL 60439-4854

www.anl.gov

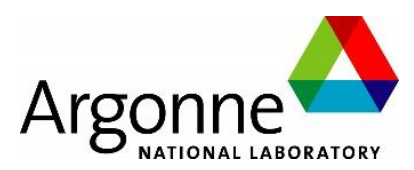

